Revue d'histoire de l'Amérique française

RAS REVUE D.HISTOIRE DE L'AMÉRIQUE FRANÇAISE

\title{
Étienne Pasquier et les libertés de l’Église gallicane
}

\section{Claude Sutto}

Volume 23, numéro 2, septembre 1969

URI : https://id.erudit.org/iderudit/302874ar

DOI : https://doi.org/10.7202/302874ar

Aller au sommaire du numéro

Éditeur(s)

Institut d'histoire de l'Amérique française

ISSN

0035-2357 (imprimé)

1492-1383 (numérique)

Découvrir la revue

Citer cet article

Sutto, C. (1969). Étienne Pasquier et les libertés de l’Église gallicane. Revue

d'histoire de l'Amérique française, 23(2), 246-284.

https://doi.org/10.7202/302874ar d'utilisation que vous pouvez consulter en ligne.

https://apropos.erudit.org/fr/usagers/politique-dutilisation/ 


\section{ÉTIENNE PASQUIER ET LES LIBERTÉS DE L'ÉGLISE GALLICANE}

Les litiges entre le pouvoir civil et le pouvoir religieux ont profondément marqué l'histoire de l'Europe depuis la fin de l'Antiquité, mais ils prirent dans chaque pays des aspects différents en fonction de l'époque, des circonstances et des hommes. Le gallicanisme en est, en France et plus tard au Canada, l'une des manifestations les plus célèbres. Il se caractérise essentiellement par une opposition concertée des clercs et des laïques aux entreprises de la papauté et par une prétendue fidélité de l'Eglise de France à la discipline ancienne de l'Eglise universelle. Source de conflits incessants entre la France et Rome pendant cinq siècles, il fit l'objet de nombreux ouvrages de droit et d'histoire, notamment à la fin du XVIe et au début du XVIIe siècles. Le plus réputé est sans conteste le Traicté des libertez de l'Eglise gallicane, de Pierre Pithou (1594).$^{1}$ Réédité et commenté à maintes reprises par la suite, il fut dès lors considéré comme le code du gallicanisme. ${ }^{2}$

Eclipsées quelque peu par sa renommée, d'un accès plus difficile aussi, les œuvres d'Etienne Pasquier n'en demeurent pas moins très importantes. Témoin attentif et perspicace des événements de son temps, leur auteur y fait montre d'incontestables qualités de juriste, d'historien, d'épistolier et de polémiste. Personnellement mêlé à de nombreuses controverses mettant aux prises Gallicans et Ultramontains, Pasquier, au cours d'une carrière littéraire exceptionnellement féconde, énuméra, justifia et défendit avec acharnement contre leurs détracteurs, les libertés réelles ou supposées de l'Eglise de France. Son œuvre témoigne à la fois de l'existence d'une longue tradition gallicane, de la confrontation de celle-ci avec la réforme tridentine et la crise nolitique et religieuse engendrée par les guerres civiles de la deuxième moitié du XVIe siècle et finalement du renouveau des études historiques et juridiques.

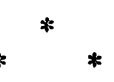

Il serait vain de considérer le gallicanisme comme un ensemble cohérent et logique d'institutions et de doctrines fixées de

1 Dans Gillot, op. cit., 310-329.

2 Il y a 23 éditions connues de l'ouvrage. 
bonne heure. ${ }^{3}$ En réalité ce n'est que peu à peu, comme insensiblement, qu'il s'est dégagé, sous la pression des événements. Il donne l'impression de n'être pendant des siècles qu'une attitude, qu'un refus d'accepter sans réticence l'autorité de Rome. Les juristes, les historiens et les théologiens gallicans s'en sont tardivement avisés et ils tentèrent dans de savants traités de lui donner plus de rigueur et de consistance. Mais ils ne discernèrent pas toujours ses multiples facettes, ses nuances, ses ambiguïtés et parfois même ses incohérences.

Il ne semble pas que l'on puisse vraiment parler de gallicanisme avant le XIVe siècle comme l'ont affirmé ses adeptes et même quelques auteurs plus récents. ${ }^{4}$ Sans doute certains de ses éléments constituants existent-ils déjà, la régale par exemple, mais l'expression "libertés gallicanes" a un tout autre sens qu'aux XVIe et XVIIe siècles. Il s'agit plutôt de la défense de ces dernières contre le roi et les grands féodaux, non contre le pape. Cependant le pouvoir monarchique et l'Eglise de France dont les liens étaient extrêmement étroits en vinrent dès l'époque de Philippe le Bel à secouer le joug d'une papauté qui n'avait de cesse d'imposer sa férule au spirituel comme au temporel. Les réflexions doctrinales des penseurs de l'époque, le Grand Schisme et la crise conciliaire fournirent à l'Eglise gallicane les arguments dont elle avait besoin pour justifier le statut particulier qu'elle revendiquait: limitation des pouvoirs du pape par le concile œcuménique, recours à la discipline ancienne de l'Eglise à laquelle la France seule était prétendument demeurée fidèle. La Pragmatique Sanction de Bourges (1438) que d'aucuns ont considérée comme l'expression la plus parfaite du gallicanisme sanctionna officiellement ces prétentions.

Mais les Gallicans ne s'accordent pas tous dans ce conflit subtil entre la papauté, l'administration monarchique et l'Eglise de France. Les libertés de l'Eglise gallicane, équivoques et vagues à souhait, peuvent être interprétées différemment en raison de la formation, des intérêts et des préoccupations de ceux qui font profession de les défendre. Les théologiens, les évêques et les

3 A.-G. Martimort, op. cit., 13, a noté avec pertinence que les mots "Gallicans" et "Gallicanisme" ne sont apparus qu'au XIX" siècle.

4 Dans ses Etudes sur le règne de Hugues Capet (Paris, Bouillon, 1903 ), ch. IV. F. Lot postule l'existence du gallicanisme dès les IX et $^{\mathbf{e}}$ siècles. Cette opinion a été nuancée par J.-F. Lemarignier dans son Cours d'histoire des institutions publiques et des faits sociaux (Paris, Les Cours de droit, 1965), 520-525. Tout en reprenant à son compte quelques-uns des arguments proposés par $\mathrm{F}$. Lot il préfère utiliser l'expression "Théocratie royale". Il faut noter que J. Lecler et V. Martin, Les origines..., estiment l'un et l'autre qu'il ne saurait être question de parler de gallicanisme avant le XIVe et même le XVe siècles. 
robins sont au XVIe siècle les principaux porte-parole de ces diverses tendances. La frontière entre eux est toutefois extrêmement mouvante et imprécise. Ils s'opposent ou s'accordent au gré des circonstances. On peut en outre distinguer chez chacun de multiples nuances et variétés. Théoriciens, mais aussi hommes d'action, confrontés perpétuellement avec des problèmes pratiques à résoudre, les Gallicans suivent attentivement les controverses politiques et religieuses et ils n'hésitent pas parfois à infléchir et à modifier les principes auxquels ils s'étaient jusque-là montrés fidèles.

Le prestige de la Faculté de Théologie est considérable en raison de sa compétence en matière de foi et de discipline ecclésiastique où personne ne songe à lui nier un rôle d'arbitre et les opinions qu'elle émet dépassent largement le cadre étroit de l'Eglise gallicane. Gardienne vigilante d'une doctrine élaborée jadis par quelques-uns de ses docteurs les plus célèbres, Gerson, d'Ailly, Almain, elle ose soutenir contre les Ultramontains que le pape ne jouit pas de la "plenitudo potestatis". Institués de Dieu au même titre que lui, les évêques échappent en grande partie à son autorité. Aussi ne peut-il rien modifier dans l'Eglise sans l'assentiment du concile œecuménique qui a le pouvoir de contrôler ses actes, et même de le déposer s'il est convaincu d'hérésie ou d'impéritie. Sa compétence en matière politique n'est pas moins restreinte. Le pouvoir séculier, distinct du pouvoir ecclésiastique, vient directement de Dieu et il est conféré au roi sans l'intermédiaire du pape. Mais il peut y avoir conflit entre les deux, notamment lorsque le monarque menace, par ses agissements, la foi de ses sujets. A l'encontre des Ultramontains qui ne reculent pas devant la déposition et au besoin devant le tyrannicide, les docteurs de la Faculté estiment que le souverain pontife ne doit intervenir que d'une manière purement "accidentelle". Sans doute peut-il excommunier le coupable et délier ses sujets de leur serment de fidélité, mais son rôle se borne à éclairer le peuple qui juge en dernier ressort du bien-fondé de sa décision et agit en conséquence. L'attitude de la Faculté à l'endroit d'Henri III et d'Henri IV était donc bien conforme à ces traditions.

Moins préoccupés que les théologiens par les questions doctrinales, encore qu'ils aient pour la plupart étudié chez eux, les évêques cherchent à défendre leurs prérogatives contre Rome et contre la monarchie qui aspirent l'une et l'autre à les contrôler plus étroitement. Aussi réclament-ils l'abolition du Concordat de Bologne et le retour au régime de la Pragmatique Sanction de Bourges qui leur assure une très large autonomie. 
Mais ce sont les membres des cours souveraines, en particulier, ceux du Parlement de Paris, qui professent le gallicanisme le plus inflexible, bien que certains d'entre eux émettent des opinions relativement modérées. Bourgeois souvent parvenus aux offices par le double jeu de la vénalité et de l'hérédité des charges, ils sont les plus fidèles serviteurs du roi à qui ils doivent et leur prestige et leur autorité. Formés par le droit romain ils participent activement à l'exercice du pouvoir législatif et ils s'emploient sans relâche à multiplier les droits régaliens et à briser peu à peu les vieux cadres féodaux. Ils soutiennent en outre que par l'onction du sacre le monarque est plus qu'un simple laïque car il tient son pouvoir de Dieu.

Aussi, aucune des idées gallicanes agitées par les théologiens et les évêques ne les laisse indifférents et il va sans dire qu'ils reprennent à leur compte, pour les outrer, celles qui leur conviennent le plus. Ils n'admettent pas que l'indépendance du roi au temporel puisse être compromise de quelque manière que ce soit; c'est pourquoi ils ne reconnaissent pas au pape le droit de l'excommunier ou de le déposer. Ils prétendent même que, par son caractère sacré d" "évêque du dehors", le souverain est le protecteur naturel, le "patron" de l'Eglise de France et qu'il leur incombe de faire respecter ce postulat. Ils suivent de très près et au besoin censurent toutes les mesures fiscales, administratives et judiciaires du pape. Ils n'enregistrent les "facultés" de ses légats qu'après s'être assurés qu'elles ne sont pas préjudiciables aux libertés gallicanes. Mais là ne se borne pas leur rôle. Par le moyen de l'appel comme d'abus, du cas privilégié et de la connaissance du possessoire des bénéfices, ils peuvent intervenir efficacement dans la plupart des questions de discipline ecclésiastique. Délivrée de la tutelle romaine depuis la Pragmatique Sanction, l'Eglise de France tendait à devenir sous cette redoutable pression un simple rouage dans l'administration monarchique.

Mais la portée immédiate de ces diverses tendances gallicanes était singulièrement restreinte par l'attitude de la monarchie. Pratiquant une politique subtile jusqu'à en être parfois déconcertante, celle-ci suit, tout au long du XVe et du XVIe siècles, une ligne de conduite empirique essentiellement dictée par ses intérêts immédiats et qui s'accommode mal des exigences des théologiens et des parlementaires. Les Gallicans les plus orthodoxes l'accusent de faire parfois le jeu de la papauté; de leur côté les Ultramontains se plaignent de son indifférence, sinon de son hostilité à leur endroit. Mais en donnant, selon les occurrences, des gages aux uns et aux autres, les rois poursuivent un 
seul but: s'assurer sans rompre avec Rome, le contrôle effectif de l'Eglise de France.

La réforme générale de l'Eglise élaborée par le Concile de Trente et imposée à toutes les nations catholiques posa à l'Eglise de France la redoutable alternative d'une adhésion ou d'un refus. De ce choix devait dépendre en dernier ressort son destin futur et par-delà, celui du gallicanisme. Aussi cette question marquat-elle profondément les débats et les conflits qui jalonnent les relations entre la France et Rome au cours de la deuxième moitié du XVIe siècle. ${ }^{5}$

En réponse aux innovations protestantes et aux vœux réitérés des catholiques, le concile raffermit les points essentiels de la doctrine et jeta les bases d'une réforme en profondeur de la discipline. Il ne trancha pas clairement la question du droit divin de l'épiscopat et celle de l'infaillibilité du pape, mais il reconnut implicitement les pouvoirs suprêmes de ce dernier en lui confiant la tâche de confirmer et de faire respecter ses décrets. De fait, sinon de droit, la thèse de la suprématie conciliaire était ainsi écartée. Sans rien céder sur le fond, l'Eglise recouvra ainsi une autorité et un prestige depuis longtemps chancelants. Cette réforme religieuse allait de pair avec une réforme politique qui la complétait et la renforçait. A l'instar des souverains laïques, la papauté acheva l'œuvre de centralisation entreprise au XIVe siècle et dota l'Eglise d'institutions administratives fortement

5 Sur le Concile de Trente et la Réforme catholique : Cristiani, Le Concile de Trente (Paris, Bloud et Gay, 1948). - Hefele-Leclercq, Histoire des Conciles (Paris, Letouzey et Ané, 1930-38), tomes IX et X. - H. Jedin, Histoire du Concile de Trente (Paris-Tournai, Desclée, 1965), tome I. En cours de publication. - L. Willaert, La Restauration catholique (Paris, Bloud et Gay, 1960). Sur sa réception en France: B. Barbiche, Correspondance du nonce en France. Innocenzo del Bufalo, évêque de Camerino (1601-1604) (Paris, De Boccard, 1964). - P. Blet, Girolamo Ragazzoni évêque de Bergame, Correspondance de sa nonciature en France (15831586) (Paris, De Boccard, 1962) ; Acta Nuntiaturæ Gallicæ, Archivum historiæe pontificiæ (1963), 413-422; Le Concordat de 1516 et la réforme tridentine, Gregorianum, XLV (1964): 241-279. - H. O. Evennett, The Cardinal de Lorraine and the Council of Trent, $A$ study in the CounterReformation (Cambridge, Cambridge University Press, 1930). - M. François, La réception du Concile de Trente sous Henri III, Atti del convegno storico internazionale, Trento, 2-6 settembre 1963 (Rome, Herder, 1965), I: $383-400$. - J. Imbert, "Les prescriptions hospitalières du Concile de Trente et leur diffusion en France", dans Revue d'histoire de l'Eglise de France, XLII (1956): 5-28. - J. Lestocquoy, "Les évêques français au milieu du XVIe siècle", dans Revue d'histoire de l'Eglise de France, XLV (1959) : 25-40; "La nonciature de France au XVIe siècle et les historiens", dans Revue d'histoire de l'Eglise de France, XLII (1956) : 229-237. - V'. Martin, Le gallicanisme et la réforme catholique contient une liste substantielle d'écrits contre le Concile, p. XXIII-XXVI. 
hiérarchisées dont les ramifications s'étendaient sans cesse. Ainsi se précisa l'identification entre l'Eglise considérée sous le double aspect d'une force politique et religieuse, et son chef. L'idée d'une Rome à la fois chrétienne et impériale tendait maintenant à s'imposer.

Un tel affermissement de la puissance romaine pouvait sembler incompatible avec le développement de l'idée nationale et la centralisation administrative des grandes monarchies. Etant donné les rapports étroits entre le temporel et le spirituel, caractérisés en particulier par l'interaction des institutions laïques et ecclésiastiques, d'aucuns craignaient qu'une réforme de cette ampleur jointe à la vieille doctrine du pouvoir direct menace la relative autonomie des clergés locaux et l'indépendance même des états. En un mot, la rencontre de deux tendances absolutistes, monarchique et pontificale, se terminerait-elle au profit de celleci, en raison même des moyens que la papauté mettait en œuvre et du prestige et de l'autorité qu'elle pouvait tirer de l'idée de réforme ? Cette inquiétude explique dans une certaine mesure le retard avec lequel certains Etats retardèrent la publication des canons conciliaires. Mais c'est de France, à cause de l'existence d'une tradition gallicane intransigeante, que vint l'opposition la plus vigoureuse. Celle des parlementaires était acquise d'emblée tant il est vrai que ceux-ci déniaient au pape toute initiative en matière disciplinaire, à plus forte raison lorsqu'elle paraissait menacer la sécurité du roi - le projet, avorté, de réformation des princes n'avait pas été oublié - et l'existence de pratiques judiciaires admises de longue date, tel l'appel comme d'abus. A cela s'ajoutaient des motifs beaucoup moins nobles. Chaque officier du Parlement de Paris jouissait du privilège de l'indult qui lui permettait, s'il était laïque, de présenter un clerc de son choix pour être pourvu d'un bénéfice. et de se présenter lui-même, s'il était ecclésiastique. Le Concile de Trente avait condamné cette pratique dès sa XIVe session en 1551. Le clergé français, de son côté, en dépit des efforts déployés par le Cardinal de Lorraine, n'avait manifesté également que peu d'enthousiasme. Sa fidélité à une conception toute différente de l'ecclésiologie l'empêchait de se rallier à l'esprit et aux décrets disciplinaires d'une assemblée qui portait en germe la condamnation du gallicanisme. Enfin la brèche apparemment infranchissable que le concile créait entre les Protestants et les Catholiques contrariait singulièrement les projets de conciliation de Catherine de Médecis. Pour ne pas s'aliéner définitivement les Huguenots, celle-ci se devait de garder ses distances avec Rome. 
Aussi la France ne donna-t-elle pas suite à la bulle Benedictus Deus et Pater de Pie IV qui invitait les souverains à faire des décrets du Concile de Trente des lois d'état. L'advertissement sur le faict du Concile de Trente de Baptiste du Mesnil ${ }^{6}$ et le Conseil sur le faict du Concile de Trente de Du Moulin ${ }^{7}$ fournirent une argumentation serrée qui fut utilisée par tous les adversaires du concile. Cependant le clergé ne pouvait demeurer longtemps insensible à l'instrument incomparable de réforme qu'étaient les canons du concile. Malgré des pressions réitérées - aux Etats de Blois (1576), à l'Assemblée du clergé de Melun (1579) - il ne put obtenir du roi qu'ils fussent reconnus officiellement. Néanmoins il en introduisit progressivement l'usage dans les diocèses et prit sur lui de les recevoir officiellement en 1615 .

La question des Jésuites était d'une incontestable gravité car elle illustrait parfaitement la controverse qui mettait en cause le statut même des ordres religieux en France. ${ }^{9}$ Hostiles à

6 (Lyon, 1564).

7 (Lyon, 1564).

$8 \mathrm{La}$ monarchie ne demeurait toutefois pas insensible aux vœux des réformateurs catholiques. L'Ordonnance de Blois (1579) qui répond aux cahiers des Etats de 1576 en témoigne. Soixante-six de ses articles, visiblement inspirés par les décrets du Concile de Trente, portent sur la réforme de l'Eglise de France (séminaires, visites épiscopales, résidence des évêques, discipline du sacrement de mariage). La Papauté s'objecta vigoureusement, mais en vain, à leur promulgation. L'Assemblée des notables de Saint-Germain-en-Laye en 1583, par la voix des juristes qui y siégeaient, conseilla au roi de poursuivre l'œuvre de réforme entreprise 4 ans plus tôt. Mais l'action concertée du nonce et des évêques empêcha la réalisation de ce projet. Sur cette question: A. Karcher, "L'Assemblée des notables de Saint-Germain-en-Laye (1583)", Bibliothèque de l'Ecole des Chartres, CXIV (1956): 114-162.

9 H. Bernard-Maitre, "Les Jésuites", dans Catholicisme (Paris, 1964), VI: 732-747. - P. Blet, "Jésuites et libertés gallicanes en 1611", dans Archivum historicum Societatis Jesu, 47 (1955) : 165-188. - J. Brodrick, Origine et expansion des Jésuites (Paris, Sfelt, 1950). - P. De Chastonay, Les Constitutions de l'ordre des Jésuites, leur genèse, leur contenu, leur esprit (Paris, Aubier, 1941). - F. de Dainville, Les Jésuites et l'éducation de la société française (Paris, Beauchesne, 1940). - P. Delattre et Alii, Les établissements des Jésuites en France depuis quatre siècles (Enghien, Intitut supérieur de théologie, 1949-1957). - A. Douarche, L'Université de Paris et les Jésuites (Paris, Hachette, 1888). - P. Dudon, Saint Ignace de Loyola (Paris, Beauchesne, 1934). - A. Favre-Dorsaz, Calvin et Loyola, Deux réformes (Paris-Bruxelles, Editions universitaires, 1951). Fouqueray, Histoire de la Compagnie de Jésus en France (Paris, Picard, 1910-1913), I \& II. - J. F. Gilmont \& P. Daman, Bibliographie ignatienne (1894-1957) (Paris-Louvain, Desclée de Brouwer, 1958). - A. Guillermou, Saint Ignace de Loyola et la Compagnie de Jésus (Paris, Le Seuil, 1960). Saint Ignace de Loyola, Constitutions de la Compagnie de Jésus (Paris, Desclée de Brouwer, 1967), édition critique par F. Courel. - L. Polgar, "Bibliographia de historia Societatis Jesu", dans Archivum historicum Societatis Jesu (1953 et sqq). 
la vocation universelle de ceux-ci, les parlementaires ne souffraient pas qu'ils puissent relever d'autorités étrangères; les évêques de leur côté ne toléraient guère leurs privilèges d'exemption et aspiraient à contrôler les monastères et abbayes au moyen de la commende; les universitaires enfin leur avaient refusé, de longue date, la permission d'enseigner en dehors de leurs couvents. Que la Compagnie de Jésus soit inconditionnellement soumise à la papauté jusqu'à devenir son auxiliaire le plus sûr dans la conduite de la réforme tridentine; qu'elle recrute surtout ses membres en Italie et en Espagne; qu'elle ait obtenu des bulles pontificales la dispensant de la dîme, la soustrayant à la juridiction des évêques et lui permettant de conférer les grades universitaires; et surtout - ambiguïté impardonnable et incompréhensible pour beaucoup - que ses membres ne soient ni moines ni séculiers mais clercs réguliers $;^{10}$ voilà qui suffisait à raviver bien des susceptibilités, à éveiller bien des craintes.

Malgré l'aide du Cardinal de Lorraine et de Mgr du Prat, évêque de Clermont, qui obtinrent du roi Henri II des lettres patentes en leur faveur en 1551, les Jésuites ne réussirent pas à briser l'opposition de la Faculté de Théologie et du Parlement de Paris et ils durent attendre jusqu'à l'Assemblée de Poissy en 1561 pour que leur projet de fonder un collège à Paris fut agréé. Et encore leur fallut-il se soumettre à d'humiliantes restrictions, celles notamment de renoncer à leur nom. Dès son ouverture le Collège de Clermont se trouva en butte aux attaques de l'Université. Forte d'une consultation du juriste Du Moulin, ${ }^{11}$ celle-ci entama des procédures pour le faire fermer. Les Jésuites n'avaient d'autres ressources que de se pourvoir en Cour de Parlement. Le procès qui s'ensuivit et où s'illustra Pasquier se termina par un ajournement de l'affaire.

L'appui non dissimulé de quelques Jésuites à la Ligue, les succès grandissants du Collège de Clermont et peut-être aussi le désir de faire oublier par un spectaculaire geste de loyalisme monarchique son passé ligueur, incitèrent l'Université à le rouvrir en 1594. Malgré un vigoureux plaidoyer d'Antoine Arnauld ${ }^{12}$ le Parlement refusa une nouvelle fois de se prononcer. Mais la tentative d'assassinat perpétrée sur la personne d'Henri IV par Chastel et les preuves plus ou moins convaincantes d'une complicité de la Compagnie dans cette affaire amenèrent l'expulsion

10 Voir sur cette question: Dom R. Lemoine, Le droit des religieux, du Concile de Trente aux instituts séculiers (Paris, Desclée de Brouwer, 1956), ch. III \& IV.

11 C. Dumoulin, Consultation de $M^{e}$ Charles Dumoulin (s.l.n.d.).

12 A. Arnauld, Plaidoyé de M. Antoine Arnawld (Paris, Mamert Patisson, 1594). 
de cette dernière du royaume..$^{13}$ Ce n'est qu'après de longues et pénibles négociations que l'interdit fut finalement levé neuf ans plus tard.

L'opposition entre les tendances gallicanes et ultramontaines prendra une ampleur insoupçonnée au moment où les conflits politiques et religieux engendrés par la deuxième Ligue en $\mathbf{1 5 8 5}$ mettront en danger les structures mêmes de l'Etat. Le dilemme entre le principe de catholicité et celui de légitimité accentuera chez les Gallicans les nuances d'opinion que le Concile de Trente avait révélées. L'unité de façade de l'idée gallicane, possible lorsque les principes essentiels du catholicisme n'étaient pas remis en question, s'effritera donc devant l'ampleur de la crise. Rempart contre Rome jusqu'alors, mais guère plus, le gallicanisme risquait maintenant de précipiter une rupture, sinon un schisme, que d'aucuns se refusaient à envisager.

C'est pour cette raison que certains ecclésiastiques, en particulier les membres de la Faculté de Théologie, également opposés au protestantisme et à la monarchie absolue, se rapprocheront des Ligueurs et même des Ultramontains dont les idées respectives sur la démocratie et le pouvoir indirect du pape convenaient davantage à leurs sentiments profonds. Sans nier l'importance des facteurs religieux, les robins, de leur côté, estimeront que ceux-ci devaient être subordonnés aux nécessités de la politique. Leur fidélité à la monarchie à laquelle ils devaient sécurité, fortune et prestige, ne se démentira pas un seul instant. Ils sentiront clairement que la restauration de l'Etat était soumise à deux conditions. La première était de rétablir la paix religieuse. C'est pour cette raison qu'ils proposèrent en 1590-1591 la réunion d'un concile national qui offrirait le triple avantage de résoudre la situation religieuse d'Henri IV, d'aplanir le problème huguenot et de rendre inutiles les interventions espagnole et romaine en France. ${ }^{14}$ La deuxième était d'identifier la cause du gallicanisme à celles de l'indépendance française et de la tradition monarchique. L'attitude des uns et des autres

13 Voir en particulier: J. Imbert, Quelques procès criminels aux XVII ${ }_{-}$ XVIIIe siècles (Paris, P.U.F., 1965), 13-20.

14 "Advertissement à la république, sur le concile national demandé par le Roy de Navarre", dans S. Goulart, Le second recueil contenant l'histoire des choses plus mémorables advenues sous la Ligue (s.l., 1590), 139-159. - J. Hotman, Advis et dessein nouveau sur le faict de la Religion en l'Eglise gallicane. Pour estre proposé au prochain Concile National ou autre assemblée des Prélats, Pasteurs et Docteurs de la dicte Eglise Gallicane, ms. de la Bibliothèque de la Société d'Histoire du Protestantisme français, 10, II, fos 75-115. - P. de la Primaudave, Advis sur la nécessité du Concile et sur la forme de le rendre légitime et libre pour l'Union chrestienne (s.l., 1591). 
devant l'excommunication du roi de Navarre par Sixte-Quint en $1585,{ }^{15}$ la condamnation d'Henri III par la Faculté de Théologie en $1589^{16}$ après l'assassinat du duc et du cardinal de Guise et les bulles de Grégoire XIV en $1591,{ }^{17}$ marquent bien, semblet-il, la frontière qui les sépare. Il faudra attendre l'échec des Etats de la Ligue, ridiculisée par la Satire Ménippée, ${ }^{18}$ et la conversion du roi pour que la brèche se résorbe. Mais l'unité retrouvée se fera au profit du gallicanisme parlementaire. Mûri depuis trois siècles dans le milieu des juristes, celui-ci s'imposera précisément dans la mesure où les robins qui le professent réussiront à dicter leurs vues aux ecclésiastiques.

15 Sanctiss. D. N. Sixti Papæ $V$ declaratio contra Henricum Borbonium assertum regem Navarræ, et Henricum item Borbonium, prætensum principem Condensum, hereticos, eorumque posteros et successores, ac liberatio subditorum, ab omni fidelitatis et obsequi debito (s.l.n.d.). Les pamphlets publiés pour la circonstance rendent parfaitement compte de l'émotion que cette bulle suscita tant chez les Ligueurs que chez les Politiques: P. de Belloy, Moyens d'abus, entreprises et nullitez du rescrit et bulle du pape Sixte Ve du nom, en date du mois de septembre 1585 (Cologne, H. Lobin, 1586). - F. Hotman, Brutum fulmen Papæ Sixti V (s.l.n.d.). - L. d'Orléans, Advertissement des Catholiques Anglois aux François Catholiques (s.l., 1586). 1589).

$16 \mathrm{~J}$. Boucher, De justa Henrici Tertii abdicatione (Paris, Nivelle,

i7 Bulles de N.S. Père le Pape Gregoire XIIII. L'une contre towtes personnes ecclésiastiques, suyvans le party de Henry de Bourbon, jadis Roy de Navarre. L'autre aux Princes, Seigneurs, Nobles et autres personnes laïques suyvans le mesme party (Tours, Jamet Mettayer, 1591). Les Parlements de Tours, de Châlons, de Bourgogne, de Normandie, le roi et l'Assemblée du clergé de Chartres se prononcèrent contre les bulles du pape tandis que le Parlement ligueur de Paris les approuvait. Le texte de ces divers arrêts se trouve dans P. Brunet, op. cit., III: 37-45 et dans Maugis, Histoire du Parlement de Paris (Paris, Picard, 1914), II : 76-77. L'affaire provoqua en outre une véritable guerre des livres entre partisans et adversaires de l'initiative pontificale: T. Berchet, Conseil chrestien sur les monitoires et menaces d'excommunication et interdiction du pape Sfondrato, dict Gregoire XIIII contre le Roy, l'Eglise et le Royaume de France (s.l., 1591). - F. de Clary, Philippiques contre les bulles et autres pratiques de la faction d'Espagne (Tours, Jamet Mettayer, 1592). - G. Coquille, "Discours des droicts ecclésiastiques et libertez de l'Eglise gallicane", dans Gillot, op. cit., 451-493. - C. Fauchet, "Traictez des Libertez de l'Eglise gallicane", dans Gillot, op. cit., 223-256. - C. Faye, Seigneur d'Espeisses, Discours des raisons et moyens pour lesquels Messieurs du Clergé ... ont déclaré les Bulles Monitoriales...... nulles et injustes et contre les droits et libertez de l'Eglise gallicane (Tours, Jamet Mettayer, 1591). - Seguier, Recueil du Plaidoié de Monsieur Seguier... contre la Bulle de Gregoire soy disant Pape 14 de ce nom (Tours, Jamet Mettayer, 1591). - M. Zampini, Défense pour les bulles monitoires de Notre Saint Père le Pape... contre les perverses intentions et pestiférés vomissements, des imposteurs qui faulsement se disent juges au Parlement de Chaalon (Paris, 1591).

18 (Ratisbonne, 1752). 
Restait à définir, à préciser, à justifier enfin, ce corps complexe de doctrines et de faits qu'étaient les libertés gallicanes et dont les événements avaient montré l'importance mais aussi la fragilité ; ce à quoi s'employèrent les historiens et les juristes qui publièrent de nombreux traités sur ce sujet à partir de 1590 . C'est à l'histoire qu'ils emprunteront la plupart de leurs arguments puisque la légitimité de l'idée gallicane reposait à la fois sur sa prétendue fidélité à la discipline ancienne de l'Eglise et sur les efforts déployés depuis longtemps par le roi, le Parlement et le clergé pour la faire respecter par la Papauté.

Certains de ces traités sont des fatras où s'accumulent sans ordre des preuves qui ne sont d'ailleurs pas toujours convaincantes. Mais leur autorité et leur rayonnement sont tels qu'ils seront réédités tout au long du XVIIe et du XVIIIe siècles et qu'ils inspireront la plupart des ouvrages ultérieurs consacrés à cette question.

A cet égard le témoignage d'Etienne Pasquier n'est pas le moindre et c'est lui que nous voudrions maintenant examiner.

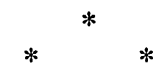

Issu d'une famille bourgeoise, Etienne Pasquier naquit à Paris en 1529. ${ }^{19}$ Après avoir étudié le droit à Paris, Toulouse,

19 A. Battista, "Pasquier e Machiavelli", dans Rivista internazionale di filosofia del diritto (1961) : 491-516. - H. Baudrillart, Etienne Pasquier, écrivain politique (Paris, Firmin-Didot, 1863). - P. Bouteiller, "Un historien du XVI ${ }^{e}$ siècle: Etienne Pasquier", dans Bibliothèque d'Humanisme et Renaissance, VI (1945) : 357-392. - G. de Bremont d'Ars, "Un Gaulois de la Renaissance, Etienne Pasquier", dans Revue des deux Mondes, LXXXVIII (1888) : 177-202.-R. Butler, Nationales und universales Denken im Werke Etienne Pasquiers (Bâle, Verlag Helbing und Lichtenbahn, 1948). - V. de Caprariis, Propaganda e pensiero politico in Francia durante le Guerre di Religione (Naples, Edizioni scientifiche italiane, 1959), I: 257-305. - A. Chamberland, "Etienne Pasquier et l'intolérance religieuse", dans Revue d'histoire moderne, I (1899): 38-49. - J. G. Espiner-Scott, "Claude Fauchet et Estienne Pasquier", dans Humanisme et Renaissance, VI (1939) : 352-360. — L. Feugère, Essai sur la vie et les ouvrages d'Etienne Pasquier (Paris, Firmin-Didot, 1848). - H. Horne, Etienne Pasquier contre les Jésuites", dans Miroir de l'Histoire CXII (1959) : 533-543. - G. Huppert, "Naissance de l'histoire en France: les "Recherches" d'Estienne Pasquier", dans Annales (1968): 69-105. F. Michaux, "Etienne Pasquier et les Jésuites", dans Revue d'histoire littéraire de la France, XXXII (1962): 87-97. - E. Pasquier, Oeuvres (Amsterdam, probablement Trévoux, Les libraires associés, 1723); Le Catéchisme des Jésuites ou examen de leur doctrine (Villefranche, Guillaume Grenier, 1602) ; Choix de lettres sur la littérature, la langue et la traduction, Publiées et annotées par $\mathrm{D}$. Thickett (Genève, Droz, 1956); Ecrits politiques, textes réunis, publiés et annotés par D. Thickett (Genève, Droz, 1966); Lettres historiques pour les années 1556- 
Bologne et Pavie sous la direction d'Hotman, Bauduin, Cujas, Alciat et Socin, il devint avocat en 1549. Cela ne l'empêcha pas de mener concurremment une carrière littéraire extrêmement féconde et variée. Ses débuts professionnels semblent avoir été assez difficiles et les suites d'un empoisonnement accidentel qui l'obligèrent à rester éloigné du barreau pendant près de deux ans, lui permirent d'achever le premier livre de ses Recherches de la France et le Pourparler du Prince qui parurent simultanément en 1560. Le plaidoyer qu'il prononça en 1565 pour l'Université contre les Jésuites lui attira l'attention du public et l'estime de ses confrères. A maintes reprises par la suite il fut amené à plaider pour la famille de Guise et le duc de Montmorency. En 1567 et 1579 il prit part aux Grands Jours de Poitiers et en 1583 à ceux de Troyes. Deux ans plus tard il devint avocat général du roi à la Chambre des Comptes. En 1588 il fut élu député du Tiers aux Etats de Blois. L'assassinat du duc de Guise auquel il était attaché ne l'empêcha pas de rester fidèle à la royauté et il suivit Henri III à Tours lorsque ce dernier y transféra son gouvernement. La Ligue le frappa cruellement en la personne de sa femme et de son fils cadet qui moururent de son fait. Il ne regagna Paris qu'en 1594 avec Henri IV. Tout en reprenant ses fonctions d'avocat, Pasquier poursuivit ses activités intellectuelles. En 1596 il livra au public quatre nouveaux livres de ses Recherches et en 1602 il composa contre la Compagnie de Jésus le Catéchisme des Jésuites. Il se retira en 1604 et mourut en 1615.

La crise profonde que traversait la société française au cours des dernières décennies du XVIe siècle ne laissait pas que d'inquiéter Etienne Pasquier chez qui la passion pour la chose publique, la fidélité au roi, le goût de l'ordre et l'amour de la "patrie françoise" étaient fortement enracinés. Il n'était pas assez proche de la Cour pour pouvoir lui imprimer directement sa marque; c'est donc par la plume qu'il s'efforça d'agir. Nulle autre discipline que l'histoire ne pouvait lui fournir l'outil dont il avait besoin pour mener à bien l'œuvre de relèvement qu'il s'était proposé d'accomplir. Il y puisa largement pour prouver l'excellence des institutions françaises. Il espérait ainsi que cette mise au jour de pratiques anciennes et ininterrompues et, partant, parfaitement légitimes, servirait de frein aux innovations des

1595, publiées et annotées par D. Thickett (Genève, Droz, 1966). - D. Thickett, Bibliographie des Oeuvres d'Estienne Pasquier (Genève, Droz, 1956); "Estienne Pasquier and his part in the struggle for tolerance", dans Aspects de la propagande religieuse (Genève, Droz, 1956), 377-402. J. Thiebot, Les idées politiques d'Etienne Pasquier, thèse dactylographiée de l'Université de Paris, Doctorat en droit français (1946). 
uns et susciterait chez les autres un sursaut de fierté patriotique, une espérance nouvelle et le désir de renouer avec une tradition dont la grandeur passée de la France était le meilleur garant. Il résuma d'ailleurs son programme dans une formule lapidaire: "Revanger nostre France contre l'injure du temps". ${ }^{20}$

Cette entreprise dont les Recherches de la France sont le fruit a certes contribué indirectement au rétablissement ultime de la légalité à la fin du siècle; mais elle marque également une étape importante dans l'historiographie française. "Avant Pasquier, écrit Huppert, l'histoire de France n'avait pas été une histoire à proprement parler, mais plutôt une sorte de sujet particulier, de thème légendaire que l'on pouvait exploiter à des fins aussi bien littéraires qu'iconographiques, dont on pouvait composer autant de versions que l'on pouvait, à condition toutefois de conserver sans changement les faits et les personnages fondamentaux."21 Parfaitement rompu aux méthodes de l'humanisme juridique dont son maître Cujas était l'un des protagonistes les plus prestigieux, Pasquier utilisa largement celles-ci. ${ }^{22}$ Ces

20 Pasquier, "Lettres", II : i, col. 28B, dans les Oeuvres, tome II. On assiste au cours de la deuxième moitié du XVIe siècle à un véritable renouveau de l'historiographie française auquel Pasquier est, bien entendu, étroitement associé. Toutefois, de grands historiens de cette époque comme Belleforest, du Haillan, du Tillet, la Popelinière, Fauchet, de Thou, sont encore, pour la plupart, fort méconnus, bien que des chercheurs, américains et italiens surtout, s'appliquent aujourd'hui à les étudier et à les révéler. Animés par un vif sentiment patriotique, serviteurs fidèles de la monarchie dont ils peuplent d'ailleurs les services, ces historiens vont mettre leur culture juridique, leur érudition, leur zèle inlassable pour la quête des documents dans les dépôts d'archives, leurs méthodes d'interprétation rigoureuse des textes, au service de l'histoire des "Antiquitez françoise" dont ils n'auront de cesse de prouver et l'excellence et la valeur exemplaire. Sur cette question voir: V. de Caprariis, op. cit., 2ème partie, chap. 2 et 3. - J. H. Franklin, Jean Bodin and the sixteenth-century Revolution in the Methodology of Law and History (New York, Columbia University Press, 1963). - G. Huppert, The New History of the French Renaissance, thèse de Ph. D. dactylographiée (Berkeley, 1962). - Cf. supra note 19 son article dans les Annales. - D. Kelley, Historical Thoughts and Legal Scholarship in Sixteenth Century France, thèse de Ph.D. dactylographiée (Columbia, 1960). - S. Kinser, The Historiography of J.A. de Thou, thèse de Ph.D. dactylographiée (Cornell, 1960); The Works of JacquesAuguste de Thou (La Haye, Martinus Nijhoff, 1966). - G. W. Sypher, La Popelinière: Historian and Historiographer, thèse de Ph.D. dactylographiée (Cornell, 1961); "La Popelinière's Histoire de France: a case of historical objectivity and religious censorship", dans Journal of the history of ideas, XXIV (1963) : 41-54; "Similarities between the scientific and the historical revolutions at the end of the Renaissance", dans Journal of the history of ideas, XXVI (1965) : 353-368.

21 G. Huppert, Naissance de l'histoire en France . ., 76.

22 Cf. P. Mesnard, "La place de Cujas dans la querelle de l'humanisme juridique", dans Revue historique de droit français et étranger, XXVII (1950) : 521-537. 
nouvelles techniques de recherche, d'analyse et d'interprétation des textes permettaient de rejeter l'événementiel à l'arrière-plan, de réduire sensiblement la part de la légende et surtout de saisir la permanence ou l'évolution des structures. Sans négliger pour autant les chroniques, histoires ou mémoires dont les auteurs avaient des objectifs différents des siens, Pasquier consulte avant tout les documents d'archives: cartulaires, actes des Parlements et des Universités, décrétales des papes, édits et ordonnances royaux, canons des Conciles, soit qu'il les ait possédés personnellement, soit qu'il les ait empruntés à ses amis Fauchet, Achille de Harlay, Faye d'Espeisses - il y aurait d'ailleurs toute une étude à faire sur ce cénacle de robins et sur leurs relations soit enfin qu'il les ait consultés à la Bibliothèque de Saint-Victor ou à celle du roi à Fontainebleau. Il n'hésite pas à reproduire - et souvent même à traduire - ceux qui lui semblent les plus significatifs. Beaucoup lui reprochèrent d'alourdir ainsi son récit et de sacrifier aux vieilles méthodes de la scolastique.

Les Recherches de la France dont la publication s'étale sur une soixantaine d'années sont un tableau des institutions, de la langue et de la littérature françaises au Moyen Age et à la Renaissance; mais ces disciplines en apparence distinctes sont dans l'esprit de Pasquier étroitement liées les unes aux autres de telle sorte qu'elles constituent chacune un aspect de la société française, transcendant à la fois règnes et dynasties, et dont les continuités fondamentales aussi bien que les mutations se manifestent depuis l'époque des Gaulois jusqu'au XVIe siècle.

Certes, Pasquier aborde son histoire avec un certain nombre de postulats qu'il entend à tout prix vérifier. Il était d'ailleurs parfaitement conscient qu'un historien ne pouvait être impartial. L'érudition en apparence désintéressée des Recherches est presque constamment au service d'une thèse. Ennemi des Monarchomaques aussi bien que des Ligueurs ou des partisans de l'absolutisme il défend le principe traditionnel d'une monarchie forte mais tempérée par la loi. ${ }^{23}$ Gardien et interprète de cette

23 Une polémique a récemment opposé le regretté V. de Caprariis, op. cit., 257 et sqq à Madame A. Battista, op. cit. Le premier a soutenu que Pasquier, d'abord opposé à Machiavel, a fini, notamment dans le Pourparler du Prince, par épouser quelques-unes de ses idées. Il signale une évolution analogue dans sa conception du pouvoir royal puisque notre auteur en vint, selon lui, à incliner peu à peu vers la monarchie absolue. Madame Battista a vigoureusement nié l'une et l'autre interprétation. Sa démonstration tend au contraire à prouver l'unité et la continuité de la pensée politique d'Etienne Pasquier qui demeura attaché jusqu'à sa mort à la forme monarchique traditionnelle. Sur cette question et sur l'antimachiavélisme en France à la fin du XVIe siècle cf.: A. Battista, "La penetrazione del Machiavelli in Francia nel secolo XVI", dans Rassegna di Politica e di Storia (1960): 
dernière, le Parlement joue un rôle éminent ${ }^{24}$ tandis que les Etats généraux n'ont pour objet que de semer le désordre. ${ }^{25}$ D'autre part Pasquier tente constamment d'inculquer à ses compatriotes la fierté de tout ce qui est authentiquement français. ${ }^{26}$ Fierté de leur langue, ${ }^{27}$ de leur littérature, ${ }^{28}$ de leur droit ${ }^{29}$ fierté de leurs origines enfin: impatienté par l'outrecuidance des Italiens qui font volontiers état de leur prestigieux passé, ${ }^{30}$ Pasquier estime que les Français ont sans doute de bien meilleures raisons de s'enorgueillir du leur. ${ }^{31}$ En bon humaniste, il ne souscrit pas au mythe de l'origine troyenne, ${ }^{32}$ mais il ne laisse

1-16; "Sull'antimachiavellismo francese del secolo XVI", dans Storia $e$ politica (1962) : 413-447. - A. Cherel, La pensée de Machiavel en France (Paris, L'Artisan du Livre, 1935). - I. Gentillet, Discours sur les moiens de bien gouverner... contre Machiavel (Genève, 1576). - C. E. Rathe prépare actuellement une édition critique de cet ouvrage, à paraître chez Droz à Genève. - R. de Mattei, "L'influenza delle vicende politico-religiose di Francia sull'antimachiavellismo cattolico di fine cinquecento", dans Studi politici (1961) : 333-356. - C. E. Rathe, "Innocent Gentillet and the first Anti-Machiavel", dans Bibliothèque d'Humanisme et Renaissance, XXVII (1965) : 186-225.

24 E. Pasquier, "Les Recherches de la France", II, iv, col. 66AB, dans les Oeuvres, tome I.

25 E. Pasquier, Lettres, IV : ix, col. 84CD.

26 Sur l'essor du sentiment national français à la fin du XVIe siècle cf.: Dupont-Ferrier, "Le sens des mots "Patria" et "Patrie" en France au début du XVIIe siècle", dans Revue historique, CLXXXVIII (1940) : 89-104. - J. Lestocquoy, Histoire du patriotisme en France (Paris, Albin-Michel, 1968), 13-59. - A. Pincon, Recherches sur l'expression du sentiment national au temps de la Ligue, Mémoire de maîtrise dactylographié (Université de Montréal, 1968). - V. L. Tapie, "Comment les Français du XVIIe siècle voyaient la Patrie", XVIIe siècle, 25-26 (1955) : 37-58. - M. Yardeni, La conscience nationale en France pendant les Guerres de Religion, 1559-1598, thèse de doctorat dactylographiée de l'Université de Paris (1965), abondante bibliographie.

27 E. Pasquier, Lettres, I: ii, col. 3BC. Sur les progrès de la langue française au XVIe siècle cf.: $\mathrm{F}$. Brunot, Histoire de la langue française (Paris, Colin, 1947), tome II.

28 Pasquier fait l'éloge de la poésie française médiévale dans le septième livre de ses Recherches.

29 E. Pasquier, Lettres, IX: i, col. 223A. Il ne nie pas l'utilité du droit romain comme discipline de formation juridique, mais il recommande vivement de le remplacer dans la pratique courante par le droit coutumier. Sur cette question cf.: P. Mesnard, "Francis Hotman et le complexe de Tribonien", dans Bulletin de la Société d'Histoire du protestantisme français (1955) : 117-137. - L. C. Stevens, op. cit. col. $1050 \mathrm{~A}$.

30 E. Pasquier, "Pourparler de la Loy", dans les Oewvres, tome I:

31 E. Pasquier, Recherches, I: ii, col. 10C.

32 Ibid., I: vi, col. $19 \mathrm{~A}$ et $19 \mathrm{C}$. Sur la question des origines troyennes, cf.: J. Barzun, The French race (New York, Columbia University Press, 1932). - A. Bossuat, "Les origines troyennes", dans Annales de Normandie (1958) : 187-197. - E. Faral, La légende arthurienne (Paris, Champion, 
pas de nous surprendre parfois par sa singulière vision de l'histoire; et les arguments qu'il utilise ne sont pas toujours convaincants. Il déplore que les Gaulois par leur mutisme ${ }^{33}$ et les historiens latins par leur mauvaise foi ${ }^{34}$ aient tant contribué à ternir l'image d'une civilisation celte qu'il jugeait conquérante et glorieuse. ${ }^{35}$ Ce raisonnement l'autorise ainsi à minimiser les victoires des légions de Jules César en insistant sur les divisions plutôt que sur la faiblesse militaire des Gaulois.$^{36}$ La revanche viendra des Francs qui libéreront la Gaule de l'occupation romaine et contribueront à la formation de la nation française. ${ }^{37}$

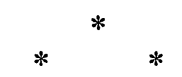

La ferveur patriotique de Pasquier est particulièrement vive lorsqu'il traite des libertés de l'Eglise gallicane. Son œuvre en témoigne en maints endroits: dans ses Lettres d'abord où il propose au jugement de ses correspondants quelques-unes de ses idées; dans le Catéchisme des Jésuites - que nous étudierons plus loin - où il met en cause l'œuvre et la doctrine de la Compagnie de Jésus; et surtout dans le livre III des Recherches où il expose au long l'histoire des relations entre la royauté, l'Eglise de France et l'Eglise universelle. Ce livre semble avoir été composé avant 1581 si l'on en croit une lettre qu'il adressa à La Croix du Maine ; ${ }^{38}$ mais il en différa la publication jusqu'en 1596. Il n'en modifia sans doute pas l'essentiel si ce n'est quelques retouches ça et là, notamment au chapitre XVIII qui fut considérablement remanié. ${ }^{39}$

Gallican fougueux, Pasquier n'en professait pas moins un catholicisme qu'il y a tout lieu de juger sincère. Résumant en quelques articles, ${ }^{40}$ au soir de sa vie, les résultats de ses recherches sur l'idée gallicane, il met en tête des libertés de l'Eglise de

1929). - G. Huppert, "The Trojan Franks and their critics", dans Studies in the Renaissance, XII (1965):227-241. - B. L. O. Richter, "The opinions of Ronsard and Belleforest on the origins of France", dans Heinz Bluhm, Essays in history and literature (Chicago, The Newberry Library, 1965), 65-80.

33 E. Pasquier, Recherches, I: i, col. 5A.

34 Ibid., I: iii, col. 14CD.

35 Ibid., I: iii.

36 Ibid., I: v.

37 Ibid., I: vii et X.

38 E. Pasquier, Lettres, IX: ix, col. 240B.

39 Il y est notamment question de la conversion et du sacre d'Henri IV, de l'attentat de Chastel et de l'affaire Florentin Jacob.

40 Ces articles font partie du chapitre xlv du Livre III des Recherches ajouté par Pasquier à partir de l'édition de 1607 . 
France, la primauté du pape. ${ }^{41}$ Ailleurs, il proteste de son attachement à la religion catholique ${ }^{42}$ et répond également de celui de ses compatriotes. ${ }^{43}$ Enfin il se défend d'avoir la moindre sympathie pour les Huguenots. ${ }^{44}$ Un tel aveu était assurément indispensable, car il lui permettait non seulement de prendre ses distances du protestantisme mais aussi de montrer qu'un Gallican pouvait demeurer malgré tout dans le giron de l'Eglise. $A$ une époque où les controverses étaient vives et l'esprit de tolérance peu répandu, il n'était pas inutile de rappeler que la remise en question des structures ecclésiastiques n'allait pas nécessairement de pair avec l'hérésie ou tout au moins le schisme, encore que d'aucuns n'aient pas voulu discerner les nuances d'une attitude aussi subtile. Loin d'insister pour l'abandon de l'obédience romaine, Pasquier veut délimiter aussi soigneusement que possible les juridictions respectives du pape et du roi dans l'Eglise de France et il prétend n'avoir d'autre intention que de concilier les parties en présence. ${ }^{45}$

Toutefois cette bonne entente ne paraissait guère réalisable. Le danger que faisait planer sur l'autonomie de l'Eglise de France la réforme tridentine avivait une méfiance traditionnelle toujours prête à se manifester par des actes concrets. Fidèle à sa méthode et à celle des autres exégètes des libertés gallicanes, Pasquier interroge l'histoire pour expliquer, mais surtout incriminer cette réforme et par conséquent justifier le bien-fondé de son engagement gallican. Ses travaux répondent constamment à ces préoccupations.

Pasquier postule que le seul régime vraiment valable que la chrétienté ait jamais connu est celui des premiers siècles de son existence. Il se caractérise par une large autonomie des Eglises nationales, une collégialité très poussée aussi bien dans celles-ci que dans l'Eglise universelle où la précellence du concile sur le pape est indiscutable, un partage harmonieux et fondé sur le

41 E. Pasquier, Recherches, III : xlv, col. 353C.

42 Ibid., III: vii, col. $190 \mathrm{~A}$.

43 Ibid., III : xiii, col. $216 \mathrm{C}$.

44 E. Pasquier, Lettres, V: viii, col. 128D-129A. Un pamphlet anonyme: L'exhortation aux princes et seigneurs du Conseil privé a soulevé et soulève encore maintes controverses. Mlle D. Thickett, Estienne Pasquier and his part in the struggle for tolerance et encore dans son édition des Ecrits politiques de Pasquier l'attribue à ce dernier et en déduit qu'il était favorable à une politique de tolérance à l'endroit des Huguenots. Cette opinion a été infirmée par la plupart des biographes de notre auteur et notamment par de Caprariis, op. cit., 152-154, note 19 et 289-299. Pour un bon résumé de la question voir: E. M. Beame, "The limits of toleration in France", dans Studies in the Renaissance, XIII (1966) : 256-260.

45 E. Pasquier, Recherches, III: xvii, col. $227-228 \mathrm{C}$ et xviii : col. $238 \mathrm{C}$. 
respect mutuel des responsabilités entre le pouvoir laïque et le pouvoir religieux. ${ }^{46}$

Ceci étant posé il ne lui restera plus qu'à tenter de prouver la véracité d'une double hypothèse: grâce à l'action conjuguée du roi, du clergé et plus tardivement du Parlement et de l'Université, les libertés gallicanes, constituées très tôt - puisqu'elles ne sont autres que le droit commun de l'Eglise primitive - ont perpétué fidèlement depuis lors, en dépit d'épreuves et parfois même d'abandons, cette ancienne discipline, dans son esprit, sinon dans sa lettre ${ }^{47}$ au contraire, l'appétit de puissance de la papauté

46 Cette recherche systématique de la discipline primitive de l'Eglise est, dans l'histoire de l'idée gallicane, un élément nouveau qui, selon $\mathrm{J}$. Lecler, op. cit., 547, est dû en partie à l'influence protestante. Si à la fin du XIVe et au début du XVe siècles les auteurs gallicans opposaient déjà le droit ancien à la fiscalité de la Cour d'Avignon, le droit commun restait pour eux le Décret de Gratien et les Décrétales car ces collections étaient muettes sur les prérogatives financières de la Papauté et elles contenaient d'importantes indications sur les élections. On opposait en somme le droit canonique aux pratiques de fait des papes. C'est ainsi qu'en 1461, le Parlement de Paris demanda à Louis XI le retour au régime de la Pragmatique Sanction de Bourges mais il ne réclama pas le rétablissement de l'ancienne discipline ("Remonstrances faictes au Roy Luys unziesme de ce nom par sa Cour de Parlement, sur les libertez d l'Eglise gallicane: en l'an MCCCCLXI", dans Gillot, op. cit., p. 1-12). A la fin du XVIe siècle cependant, grâce aux travaux des auteurs protestants et aux progrès de la science canonique, les Gallicans vont être amenés à reprendre les diverses collections de droit ecclésiastique de façon à en dégager les caractères anciens, donc à leurs yeux, valables. C'est ainsi qu'ils postuleront l'existence d'une liberté primitive, antérieure au développement de la puissance pontificale et dont on retrouve les traces dans toutes les collections canoniques jusqu'aux Décrétales et même au-delà. Pour Leschassier, "De la liberté ancienne et catholique de l'Eglise gallicane", dans Gillot, op. cit., appendice, 1-13, l'ancienne discipline ne se trouve pas consignée dans la Dionysiana ou dans le Décret qui, selon lui, se ressentent déjà de l'influence romaine, mais plutôt dans un hypothétique code de l'Eglise universelle où sont comprises les décisions des 4 premiers conciles œecuméniques et dans un non moins hypothétique code de l'Eglise gallicane. P. Pithou, op. cit., $\mathrm{n}^{0}$ XLI, de son côté, croit retrouver cette ancienne discipline dans la Dionysio-Hadriana.

47 Pasquier estime que les libertés gallicanes sont de véritables droits; ce n'est que "par une grande abondance d'humilité et d'obéissance envers le Saint Père" qu'on les appelle privilèges. Recherches, III: xxix, col. 272C-273A. Pour P. Pithou, op. cit., $n^{\circ} \mathrm{I}$, les libertés gallicanes sont des franchises naturelles. Quant à Leschassier, op. cit., 10-11, il établit une subtile distinction entre les privilèges canoniques qui sont de véritables libertés et les privilèges apostoliques qui sont des privilèges proprement dits. Les Gallicans s'entendaient également pour affirmer que les libertés gallicanes ne pouvaient être dénombrées. Pasquier, op. cit., III : xlv, col. 353CD$354 \mathrm{ABC}$, en distingue douze fondamentales mais il y en a bien davantage dans ses Recherches; A. Hotman, op. cit., 366, estime que l'on ne peut pas les "déclarer par nombre comme l'on feroit des privilèges de la France"; P. Pithou, op. cit., en énumère quatre-vingt trois, il déclare toutefois que les "particularitez de ces libertez pourront sembler infinies", $n^{\circ}$ II; J. 
l'a conduit, par degrés, à abandonner celle-ci, à renier donc la mission à laquelle elle avait été destinée, à usurper des pouvoirs qui n'étaient pas siens, à aspirer enfin au grandiose dessein d'une prépotence spirituelle et temporelle dont le Concile de Trente semble préfigurer la réalisation.

L'étude du destin divergent de ces deux options devait amener Pasquier à procéder largement par voie de comparaison. La méthode était assurément féconde. Elle l'obligeait en effet à ne pas considérer l'Eglise de France comme une entité en marge de l'Eglise universelle, à expliquer l'influence réciproque de l'une sur l'autre, à mesurer avec plus de précision tout ce qui les séparait. Elle n'allait toutefois pas sans risque car elle incitait l'auteur à étaler sans retenue son parti-pris.

L'étude de la place du pape dans l'Eglise et de ses relations avec la France est évidemment essentielle pour son propos et elles le préoccupent donc au premier chef. Ne sont-ce pas les points qui suscitent les polémiques les plus âpres entre Gallicans et Ultramontains? Il ne songe pas d'ailleurs à taire son admiration pour la papauté qui, universellement combattue, non point par la force des armes "ains par les spirituelles, par opinions d'uns et d'autres: les aucuns luy donnans (ainsi que quelques-uns estiment) plus qu'il ne luy appartenoit, ores qu'il luy en appartint beaucoup, et les autres beaucoup moins" ${ }^{48}$ et aussi en dépit de ses modestes origines est parvenue à de tels sommets et ce "par la seule parole qui procède de sa puissance absolue". ${ }^{99}$ Pasquier retrace en quelques chapitres les principales étapes. Le prestige de son siège épiscopal, la préséance arrachée aux patriarches orientaux et la possession exclusive du titre de pape, assurèrent à l'évêque de Rome la suprématie spirituelle dès les premiers siècles du christianisme..$^{50}$ La conquête de l'hégémonie temporelle suivit de près car il était la seule autorité qui comptât vraiment dans Rome après l'abandon de cette ville par l'administration impériale et la chute subséquente de l'Empire. La constitution de l'Etat pontifical au VIIIe siècle couronna cette double évolution. ${ }^{51}$ Par la suite, la prétention de régenter, et au besoin d'excommunier et de déposer les empereurs, ${ }^{52}$ les inter-

\footnotetext{
Leschassier, enfin, composa à ce sujet un petit traité: Contre ceux qui disent que les Juges de ce Royaume doivent dire et compter, quelles, et combien sont les libertez de l'Eglise gallicane et de quelle authorité elles sont procédées (Paris, Pierre Lamy, MDCLII).

48 E. Pasquier, op. cit., III: viii, col. $189 \mathrm{~A}$.

49 Ibid., III: col. 153B.

50 Ibid., III: i, ii, iii, v.

51 Ibid., III: iv.

52 Ibid., III : xiv, col. 218CD-219BC.
} 
ventions en Italie à la faveur des luttes entre Guelfes et Gibelins, ${ }^{53}$ les Croisades, ${ }^{54}$ la fondation de nombreux ordres religieux qui lui étaient tout dévoués, ${ }^{55}$ les compilations canoniques, ${ }^{56}$ l'envoi de légats, ${ }^{57}$ les évocations en Cour de Rome, ${ }^{58}$ les réformes administratives et financières du XIVe siècle ${ }^{59}$ et finalement le Concile de Trente, ${ }^{60}$ sont autant de manifestations du dynamisme mais aussi de l'insatiable appétit de puissance de la Papauté.

Il était assurément dans l'ordre des choses qu'en sa qualité de successeur de saint Pierre le souverain pontife occupât la première place dans l'Eglise. Qu'il ait atteint à un si haut degré de puissance, au temporel comme au spirituel, au point d'en avoir complètement oublié le sens de sa mission primitive, voilà par contre qui ne laissait pas d'être inquiétant. Quelles qu'aient été ses initiatives en la matière, Pasquier ne lui en attribue pas l'entière responsabilité car maints facteurs ont pu infléchir son destin. Ainsi Dieu a-t-il lui-même permis que sa mission ne s'accomplisse pas sans imperfections. ${ }^{61}$ Mais notre auteur ne croit pas qu'une action providentielle directe suffise à tout expliquer; à un phénomène historique il convient de rechercher d'abord des causes historiques même si, en dernier ressort, celles-ci résultent de desseins divins. Et les exemples ne manquent pas: "L'authorité de S. Pierre, les martyrs continuels et de suite que souffrirent nos premiers Saincts Peres de Rome jusques à Silvestre, la Religion vray et catholique, en laquelle leur postérité fut ferme contre les furieux assauts des hérétiques, l'humanité dont ils avoient embrassé tous les Evesques à tort affligez, la ruine des Eglises apostoliques du Levant, premierement par les hérésies en après par les Mahométistes, les particularitez et divisions des Princes Chrestiens en la France, Allemagne et Italie, l'ambition desréglée et ignorance de nos Prélats, la desbauche de nostre Eglise gallicane procurée par nos Roys mesmes, l'humble soumission du commun peuple: Toutes ces particularitez mises ensemble furent de tel effect et vertu, que non seulement le pape fut jugé avoir toute puissance sur les Evesques, mais

53 Ibid., III : xiv, col. $220 \mathrm{AB}$.

54 Ibid., III: xiv, col. 219D-220A et xix, col. 239BC.

55 Ibid., III: xix, col. 239D-240AB.

56 Ibid., III : xiv, col. $222 \mathrm{ABC}$.

57 Ibid., III: xxi, col. $248 \mathrm{AB}$. Pasquier ajoute que la chose fut d'autant plus aisée en France "qu'avecques l'ambition s'estoit en ce temps-là logée l'ignorance chez nous". Ibid., III: xi, col. 206B.

58 Ibid., III : xx-xxi.

59 Ibid., III : xxv.

60 Ibid., III : xxxiv.

61 Ibid., III : col. 155A-156A. 
aussi sur tous les Princes et Potentats de la Chrestienté."62 Poussant plus loin son analyse Pasquier en vient à discerner l'existence de constantes historiques qui expliquent dans une certaine mesure le rôle de la papauté. Il appert d'abord que la faiblesse politique des états favorise l'immixtion de Rome dans les domaines qui leur appartiennent normalement; il n'en veut pour exemple que la chute de l'Empire romain et les carences des derniers Carolingiens, des Empereurs allemands et des premiers Capétiens. ${ }^{63}$ Il est non moins évident que les interventions abusives des laïques sur les privilèges ecclésiastiques provoquent "par un jugement caché de Dieu, et à vray dire une justice de Dieu exercée par l'injustice des hommes" ${ }_{64}$ un déséquilibre qui appelle à son tour une réaction en sens inverse; les papes tentent alors de rehausser et même d'exagérer et leur prestige et leur autorité par des initiatives qu'ils jugent être à la mesure de l'affront subi, comme la réforme grégorienne, ${ }^{65}$ les croisades, la centralisation administrative du XIVe siècle, ${ }^{66}$ tandis que les clergés locaux se tournent tout naturellement vers Rome pour sauvegarder leurs privilèges menacés. ${ }^{67}$

Ces réflexions de Pasquier sur les causes et les divers aspects de la grandeur romaine n'ont d'autre objet que de lui permettre de faire ressortir, par un effet de contraste, la profonde originalité des libertés de l'Eglise gallicane. Il constate d'abord qu'elles ont de tout temps constitué un rempart fort efficace contre la papauté dont elles restreignent les prétentions, religieuses autant que politiques, si prestigieuses et si anciennes soient-elles. ${ }^{68} \mathrm{Bien}$ que sa compétence exclusive en matière de foi ne soit nullement remise en cause, "l'évêque de Rome" n'a en revanche que des pouvoirs disciplinaires insignifiants sinon inexistants sur les autres prélats. Pasquier s'appuie sur les écrits des Pères de l'Eglise et sur les canons des premiers conciles pour démontrer qu'ils ne tiennent leur charge que de Dieu, au même titre que lui. ${ }^{69}$

62 Ibid., III : xiv, col. 217B.

63 Ibid., III : iv, xi, xii, xiv.

64 Ibid., III: xv, col. $222 \mathrm{~A}$.

65 Ibid., III : xiv, col. 221C.

66 A l'encontre de l'opinion commune Pasquier estime que le transfert de la Papauté de Rome à Avignon sous le règne de Philippe IV le Bel a été en définitive néfaste pour la cause de l'Eglise gallicane. Ibid., III : xxiii, col. $252 \mathrm{C}$.

67 C'est ainsi que les abus des rois précipitèrent la décadence des élections et firent progresser la pratique des nominations pontificales. Ibid., III : xii, col. $214 \mathrm{C}$.

68 Opinion partagée par la plupart des Gallicans. Toutefois, l'ancien ligueur A. Hotman, op. cit., 377, estime qu'il est dangereux "de trop déprimer la dignité du Pape".

69 E. Pasquier, op. cit., III : xlv, col. 353D-354A. 
Non seulement il ne peut intervenir dans leur élection mais il doit encore laisser à un concile national ou provincial la tâche de régler les différends qui peuvent survenir entre eux. ${ }^{70}$ Cette situation privilégiée des évêques rejaillit sur le concile œcuménique dont ils font partie. Il est d'ailleurs d'usage en France depuis les premiers siècles du christianisme de lui subordonner le pape pour les questions disciplinaires et d'accorder à celui-ci une préséance et une autorité morale auxquelles ses qualités de chef spirituel et de successeur de Saint Pierre lui donnent droit. Ce dédoublement de l'autorité religieuse a été sanctionné officiellement par l'Eglise au XVe siècle et Pasquier ne se fait pas faute d'utiliser deux témoignages prestigieux de cette époque à l'appui de ses dires. Le premier, extrait des canons du Concile de Bâle, montre que le pape a préséance sur chaque chrétien, clerc ou laïque, mais non sur tous, c'est-à-dire sur le corps ecclésial. ${ }^{71}$ Quant au second, il l'emprunte à Gerson. Ce dernier accorde au Concile le pouvoir de déposer, le cas échéant, le pape; il ne saurait toutefois supprimer sa fonction qui est essentielle. ${ }^{72}$ D'ailleurs, ajoute Pasquier, le souverain pontife est un homme et il peut par conséquent faillir; ses erreurs ne doivent donc en rien entacher la dignité du Saint-Siège. ${ }^{73}$

Son autorité dans le domaine politique est pratiquement inexistante encore qu'elle puisse dépendre, dans une certaine mesure, de la personne sur laquelle elle est susceptible de s'exercer. Avec un détachement qui confine au mépris, Pasquier laisse au pape la possibilité de censurer les autres souverains à la seule condition que ses sanctions soient justifiées et qu'elles demeurent dans les limites de la bienséance. ${ }^{74}$ Singulière remarque certes qui ne doit toutefois pas, semble-t-il, être interprétée comme une concession au pape mais plutôt comme la constatation d'un état de fait, et notamment de la situation privilégiée du roi de France. ${ }^{75}$ Celui-ci, en effet, ne tient de personne au temporel, si ce n'est de Dieu. ${ }^{76}$ Voilà assurément une liberté d'une extrême importance; les événements de la deuxième moitié du XVIe siècle expliquent d'ailleurs facilement la considération dont elle était l'objet. Pasquier prétend en tout cas qu'elle est attachée à la monarchie de toute ancienneté: son existence est attestée dès l'époque mérovingienne; ${ }^{77}$ Innocent III

70 Ibid., III : vii, col. 183C.

71 Ibid., III : xxvii, col. $268 \mathrm{C}$.

72 Ibid., III : xvi, col. 226B.

73 Ibid., III : xiv, col. $221 \mathrm{AB}$.

74 Ibid., III: xviii, col. 238D-239A.

75 Ibid., III: xvi, col. 223D-224C.

76 Ibid., III : xiii, col. 216D.

77 Ibid., III : vii-viii. 
la reconnaît officiellement au XIIIe siècle ${ }^{78}$; au XVIe encore, le Parlement de Paris l'invoque lors des procès de Jean Tanquerel et de Florentin Jacob. ${ }^{79}$ Trois conséquences en découlent: le royaume ne peut être mis en interdit ou transféré à un autre 80 et le roi excommunié de la seule main du pape. ${ }^{81}$ Certes Pasquier ne lui nie pas le droit de lancer des sanctions spirituelles puisqu'elles sont de son ressort; il ne peut toutefois les imposer avant d'en avoir soumis préalablement la teneur à un concile national, habilité à décider, en dernier lieu, de leur bien-fondé et de leur opportunité.82 Mais n'est-ce pas se leurrer que d'envisager une collusion entre le pape et l'Eglise de France puisque celle-ci, comme nous le verrons plus loin, est étroitement soumise au roi? Advenant qu'une telle éventualité se produise, ce dernier serait à la fois juge et partie.

Cet effacement de la papauté n'indiquait-il pas que le concile œcuménique, nanti à ses dépens d'une autorité accrue, puisse promulguer des directives avec force exécutoire même en France? L'institution, il est vrai, y avait ses lettres de noblesse et Pasquier remarque que les canons de Nicée, de Constantinople, d'Ephèse et de Chalcédoine, pour la foi, ceux de Constance et de Bâle, pour la discipline, étaient particulièrement vénérés. ${ }^{83}$ Toutefois, ce prestige, pour incontestable qu'il fût, n'était qu'une façade et il cachait mal une réalité qui était souvent tout autre. L'appel au futur concile pour régler les litiges entre les juridictions laïques et ecclésiastiques était en pratique remplacé depuis le XIVe siècle par l'appel comme d'abus; ${ }^{84}$ les décrets de Constance et de Bâle n'étaient passés dans la législation française que par la Pragmatique Sanction de Bourges; ${ }^{85}$ mais surtout, la vigoureuse reprise en main du concile par le pape au XVIe siècle signifiait clairement que l'allégeance gallicane envers celui-là présentait des risques et pouvait donc être remise en question, ce qui n'allait pas sans poser de sérieuses difficultés. L'attitude de Pasquier face au Concile de Trente illustre bien le souci constant qu'avaient les Gallicans de maintenir le fragile équilibre entre la sauvegarde de la supériorité conciliaire, la défense des libertés de l'Eglise de France et l'affirmation sans équivoque de la communauté de foi avec Rome. A vrai dire la complexité de

78 Ibid., III : xvii, col. $228 \mathrm{C}$.

79 Ibid., III: xviii, col. 235-237.

80 Ibid., III: xlv, col. 353CD.

81 Ibid., III : xviii, col. 229D-230D.

82 Ibid., III: xvi, col. $225 \mathrm{~A}$.

83 Ibid., III: xxxiii, col. 291A.

84 Ibid., III: xxxiii, col. 290BC.

85 Ibid., III : xxvii. 
la question était telle que seule une solution hybride pouvait lui être apportée. Les décrets dogmatiques du concile s'imposent d'eux-mêmes; ${ }^{86}$ ceux qui concernent la discipline doivent être préalablement soumis au roi avant d'être reçus en France, ${ }^{87}$ encore faut-il qu'ils n'infirment pas les libertés gallicanes ou que leur sagesse soit telle qu'elle force à l'acquiescement. Ils ne pouvaient donc que se réclamer "ou de la Saincte Escriture, ou des Saincts Decrets ou des Concils approuvez, ou bien qu'ils eussent quelque raison de leur dire". .88

Ces sérieuses réserves à l'endroit du Concile signifiaient-elles qu'il était, à toutes fins utiles, sans objet? Assurément non. Pasquier ne prend pas peu de peine à tenter de démontrer que la supériorité conciliaire était l'une des libertés essentielles. L'abandonner, c'eût été renoncer à toute la tradition ecclésiale dont la Pragmatique Sanction était l'aboutissement, oublier qu'on la considérait en France comme le seul moyen valable de réformer l'Eglise - quitte d'ailleurs à la brandir comme menace dans les moments opportuns - , et au pire reconnaître, au moins implicitement, la toute-puissance du pape. Mais Pasquier avait suffisamment de sens historique pour comprendre que les institutions sont une réalité vivante, étroitement dépendantes de ceux qui les utilisent; elles peuvent donc, selon les occurrences, ne plus répondre à ce que l'on attend d'elles. Il savait clairement que le jeu était faussé à Trente parce que - signe des temps? - le pape en était le meneur. Quelque respect qu'il eût pour les précédents, pour la force exemplaire de l'histoire, peut-être sentait-il tout ce que la notion même de supériorité conciliaire avait de chimérique à son époque. C'est probablement la raison pour laquelle il accorde tant d'importance aux institutions proprement françaises, et en particulier aux rapports entre le roi et l'Eglise de France.

C'était toucher là une question d'autant plus délicate qu'elle mettait en cause celle de la centralisation monarchique. Il ne faisait aucun doute en tout cas que la mise en tutelle graduelle du clergé français était une pomme de discorde entre Ultramontains et Gallicans, et elles suscitaient même chez ces derniers des réactions divergentes. Les ecclésiastiques - on l'a vu - la condamnaient. Les parlementaires qui en étaient le plus souvent l'instrument n'avaient de cesse qu'elle se réalise, encore qu'ils ne s'accordassent pas toujours sur l'amplitude qu'il convenait de lui donner. Tout en reconnaissant volontiers les droits éminents

86 Ibid., III : xlv, 354A.

87 Ibid., III : xxxiii, col. 291A.

88 Ibid., III : xxxiv, col. $294 \mathrm{CD}$. 
du roi en matière de discipline ecclésiastique, certains d'entre eux - dont Pasquier -, plus modérés, désiraient les contenir en deçà des bornes fixées par la tradition gallicane.

Il n'en demeure pas moins, constate notre auteur, que tous les souverains - et à plus forte raison le roi de France - se sont mêlés "des choses sacrées et spirituelles pour se rendre plus reverez de leurs sujets ..." ${ }^{89}$ Fils aîné, gardien," "général et superintendant" ${ }^{11}$ de l'Eglise gallicane, ce dernier jouit en fait d'attributions comparables à celles du clergé; ${ }^{92}$ seul il peut être oint avec l'huile de la sainte-ampoule et guérir des écrouelles. ${ }^{93}$ C'est d'abord à l'investiture divine qu'il doit ses privilèges, mais aussi à leur pratique ininterrompue depuis le VIe siècle.94 Les uns ressortissent au domaine législatif : tels, l'usage courant chez les rois mérovingiens et carolingiens de convoquer des conciles nationaux et d'en approuver les décisions ${ }^{95}$ - la Pragmatique Sanction de Bourges en est d'ailleurs, sous Charles VII, un exemple tardif -, les constitutions impériales et les édits royaux sur la discipline ecclésiastique, ${ }^{96}$ le droit de contrôle sur les mandats des légats par les souverains valois ${ }^{97}$ et enfin le pouvoir de ceux-ci de donner force de loi aux canons disciplinaires d'un concile œcuménique ou, le cas échéant, de les repousser. ${ }^{98}$

D'autres sont d'ordre judiciaire: Pasquier se félicite du recul des officialités dont l'influence était telle, au Moyen Age, que les "fauxbourgs estoient trois fois plus grands que la ville"; ${ }^{99}$ mais il se garde bien de réclamer leur suppression. Il se borne à constater que leur compétence ne s'étend plus qu'aux clercs sauf en matière de mariage et "autres choses sacrez" tandis que le roi connaît désormais des causes réelles et criminelles des ecclésiastiques. ${ }^{100}$ De toute manière, que les procès soient instruits devant un tribunal laïque ou devant un tribunal ecclésiastique, ils ne peuvent être portés en appel à Rome. ${ }^{101}$ C'est toutefois l'appel comme d'abus qui est, pour Pasquier, le symbole le plus tangible de l'activité judiciaire du roi en matière ecclésiastique;

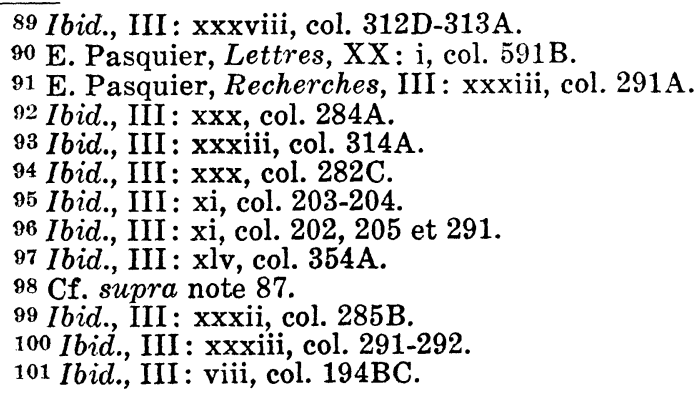


il ne croit pas "qu'il y ait plus grand et fort nerf de nostre Republique Françoise, ny plus asseuré rempart que cettuy".102 Il permet en effet au souverain ou plutôt à ses "gens", c'est-à-dire aux membres du Parlement, de juger les plaintes portées contre les actes des légats, des ordinaires et du pape quand ceux-ci enfreignent les lois et coutumes du royaume. Il est donc particulièrement expédient de l'utiliser contre le Concile de Trente. ${ }^{103}$

Il ne faisait toutefois aucun doute que, de tous ces privilèges, c'était la régale qui investissait le roi de l'autorité et du prestige les plus considérables. Ne lui permettait-elle pas, selon les cas, de percevoir les fruits d'un évêché vacant (régale temporelle) ou d'y effectuer certaines nominations (régale spirituelle)? Toujours soucieux de ne point dépouiller l'Eglise de France de ses droits traditionnels, même aux mains du roi, Pasquier paraît avoir conçu quelque gêne à l'endroit de cette institution, redoutable en raison des abus qu'elle pouvait facilement engendrer. Il ne ménage pas en tout cas ses efforts pour trouver des arguments susceptibles d'en prouver l'excellence, à ses lecteurs comme sans doute... à lui-même. Il insiste sur son ancienneté: elle apparaît en effet, prétend-il, à l'époque de Clovis; sur son caractère strictement français: loin d'être une concession de la papauté, elle est au contraire "annexée à la Couronne de France comme l'un de ses plus beaux fleurons" ${ }^{104}$ et en dépit de quelques ressemblances elle diffère notablement du droit d'investiture pratiqué par les empereurs allemands du XIe siècle; sur sa parfaite orthodoxie enfin puisque la papauté l'a reconnue de bonne heure. ${ }^{105}$

Cet inventaire des droits du roi était, à n'en point douter, destiné aux Ultramontains; il s'adressait également, selon toute probabilité, aux Gallicans les plus intraitables pour leur rappeler les limites qu'il ne convenait pas de franchir. ${ }^{106}$ La fidélité de

102 Ibid., III : xxxiii, col. $290 \mathrm{~A}$.

103 Ibid., III : xxxiii, xxxiv. Pour tout ce qui concerne l'appel comme d'abus, cf.: C. Fevret, Traitté de l'abus et du vrai sujet des appellations qualifiées de ce nom d'abus (Dijon, 1653). - R. Genestal, Les origines de l'appel comme d'abus (Paris, P.U.F., 1951). - R. Naz, "Appel comme d'abus", dans Dictionnaire de droit canonique (Paris, Letouzey et Ané, 1937), I, col. 818-827.

104 Ibid., III : xxxv, col. 295B.

105 Ibid., III : xxxv à xxxix. Cf. également: J. Gaudemet, "Régale", dans Dictionnaire de droit canonique (Paris, Letouzey et Ané, 1959-1960), VII : col. 493-532. - E. Michellet, Du droit de régale (Ligugé, 1900).

106 P. Pithou, op. cit., no LXVIII, concevait fort bien que le roi use du droit de nomination; J. Leschassier, De la liberté ancienne ... 11-12, estimait qu'il avait l'autorité de Josias "pour faire baptiser et prescher, et faire garder le droit de l'Eglise". 
Pasquier aux idéaux traditionnels de la royauté française, dans la mesure où ils étaient précisément incompatibles avec la notion de pouvoir absolu, l'empêchait d'acquiescer à la centralisation monarchique, et partant, à la mise en tutelle de l'Eglise de France qui, d'aucuns le pensaient, devait s'ensuivre. Il n'admettait pas que le roi puisse - sans risquer de rompre un équilibre toujours précaire entre le spirituel et le temporel utiliser à son profit exclusif des privilèges qui comptaient parmi les coutumes les plus anciennes et les plus vénérées. Défenseur de l'Eglise gallicane, certes il l'était, il ne pouvait toutefois se targuer d'en être le maître. Protéger le clergé, le guider même lorsqu'il vascillait, mais le laisser, dans la mesure du possible, conduire librement ses affaires, voilà le programme que lui assigne Pasquier. C'est que les droits de l'Eglise gallicane autant que ceux du roi d'ailleurs - sont sacrés: "il ne faut rien oster à l'Eglise pour le donner par une nouveauté à nos Roys, ny leur oster pour le donner à l'Eglise. Le plus seure guide de nos actions est la longue ancienneté." 107 Et pour Pasquier le droit le plus intangible est la liberté d'élection. Il invoque à cet effet le témoignage de saint Bernard pour lequel "il ne faisoit aucun doute qu'il n'appartenoit au Roy d'interposer son authorité en telles eslections et que qui eust voulu soustenir le contraire, il offensoit les Loix du Royaume". ${ }^{108}$ Il suffit, en fin de compte, de s'en tenir, ou plutôt de revenir, à la pratique des Capétiens dont le but fut toujours "de ne rien perdre de leurs droicts et néantmoins remettre toutes les choses de l'Eglise en leur ordre... car ils laissèrent les eslections au clergé". ${ }^{109}$ Cette prise de position ferme, sans ambiguïté, explique que Pasquier ait condamné - en termes voilés toutefois car il était loi du royaume - le Concordat de Bologne "fondé seulement sur les abus qui se faisoient aux eslections, lesquelles estoient instituées de droict divin". ${ }^{110}$

$$
* * *
$$

L'une des raisons qui avait incité Pasquier à consacrer tout un livre de ses Recherches de la France aux libertés de l'Eglise gallicane était de les protéger contre les menées de la Compagnie de Jésus; il les jugeait d'autant plus redoutables que cette dernière, selon lui, professait des "propositions toutes contraires aux nostres, à la subversion de nostre estat".111 Il semblait

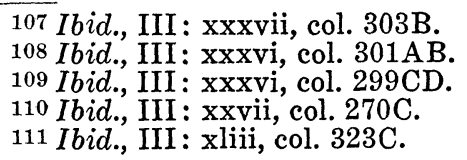


évident toutefois qu'une telle entreprise, pour valable qu'elle fût, n'atteignait que partiellement au résultat recherché. $\mathrm{Ne}$ convenait-il pas de s'en prendre à la racine même du mal, de présenter en quelque sorte l'autre volet du diptyque, bref, de débusquer l'adversaire, de le dénoncer, de se l'assujettir enfin? Tel fut l'ambitieux dessein de Pasquier et il n'y a rien d'étonnant à ce qu'il se soit efforcé de le mener à bien; son rôle au cours du procès de 1565, la hargne incessante dont il poursuivit la Compagnie aussi bien d'ailleurs que le ressentiment que celle-ci en conçut, l'y désignaient. C'est ainsi qu'il consigna dans ses Lettres, mais surtout dans le Plaidoyer et le Catéchisme, le résultat de ses propres observations et réflexions autant que nombre d'idées couramment acceptées, sur les structures, les agissements et les doctrines avancées par les Jésuites.

Il réussit dans une certaine mesure à faire la part de la vérité historique et son analyse ne manque ni de finesse ni de clairvoyance. Il comprit que les Jésuites étaient à la fois l'âme dirigeante et les acteurs de la Réforme catholique, mouvement centripète qui ne s'accommodait ni des nationalismes naissants ni des institutions particulières des Eglises locales; il savait enfin que, cravachée par eux, la papauté se ferait plus âpre et plus exigeante, qu'elle tenterait de reprendre en main la direction spirituelle et temporelle de la "Respublica christiana" qui lui avait peu à peu échappé.

Mais Pasquier ne vise pas qu'à l'analyse objective car chez lui l'historien et l'érudit ne sauraient être dissociés du pamphlétaire. Tout ce qu'il écrit se veut une mise en garde de ses compatriotes contre un danger qui lui paraît particulièrement inquiétant. Plus souvent qu'à son tour il manie l'invective et le sarcasme, il se laisse guider par un esprit de parti pris qui ne connaît aucune borne, il accueille sans discernement tous les témoignages hostiles aux Jésuites, qu'elles qu'en soient la source et la teneur. Par là même, il est conduit à des affirmations gratuites, à des généralisations hâtives et sans fondement. Il était d'ailleurs conscient de la dureté, de la partialité de ses propos et il n'est pas d'efforts qu'il n'ait fournis pour se justifier. Dans une lettre à Bellièvre il écrit que ce n'est pas la haine de la Compagnie de Jésus mais bien l'amour de la patrie qui l'a poussé à agir de la sorte. ${ }^{112}$ Ailleurs, il consent à reconnaître l'utilité des Jésuites dans la lutte contre l'hérésie. ${ }^{113}$ Enfin, c'est un singulier hommage qu'il se rend à lui-même lorsqu'il invite

112 Bibliothèque Nationale, département des mss., Ancien fonds français, 15900 , fo 367 .

113 E. Pasquier, Lettres, XX: i, col. 593BC. 
ses adversaires à répondre à son Catéchisme non par des pamphlets sans substance mais par des ouvrages dont l'érudition serait à la mesure de la sienne! 114

Ses contemporains ont vite compris tout l'intérêt qu'ils pouvaient tirer de ses écrits et les traductions anglaises, allemandes et néerlandaises du Plaidoyer et du Catéchisme témoignent éloquemment de l'intérêt que Catholiques et Protestants de tout poil lui portaient. ${ }^{115}$ Les Jésuites ne s'y trompèrent pas non plus et ils reconnurent en lui l'un de leurs adversaires les plus acharnés. Aussi leurs porte-parole ne laissèrent guère passer l'occasion de lui donner la réplique. ${ }^{116}$

Composés à trente-sept ans d'intervalle ces deux ouvrages permettent de saisir l'évolution d'une pensée et d'une argumentation qui se précisent à la lumière du rôle croissant de la Compagnie de Jésus dans les affaires politiques et religieuses de l'Europe.

Le Plaidoyer ${ }^{117}$ est un opuscule qui porte la marque d'une rédaction trop souvent hâtive, superficielle et tendancieuse. La documentation est sommaire car le secret dont les Jésuites entouraient la gestation et le contenu de leurs Constitutions en rendait la connaissance très approximative. Force fut donc à Pasquier de recourir aux renseignements - sujets à caution si l'on en juge par le résultat, à moins qu'il ne les ait délibérément faussés - qu'il tenait du père Paschase Broet.118 Pasquier tente

114 Ibid., XXI: iii, col. 637CD-638ABC.

115 Cf. D. Thickett, Bibliographie ..., 117-141.

116 F. Garasse, Les Recherches des Recherches et autres ouvres de Me Estienne Pasquier (Paris, Sébastien Chappelet, MDCXXII). Le père Richeome qui écrivait sous divers pseudonymes (de Beaumanoir, de la Fon, de la Grâce, des Montaignes) semble avoir été le porte-parole officiel de la Compagnie de Jésus contre Antoine Arnauld, Simon Marion et surtout Etienne Pasquier. Ce dernier d'ailleurs, dans une lettre à Saincte-Marthe, Lettres, XXI: ii, col. $632 \mathrm{AB}$, indique qu'il n'était pas dupe de cette identité à facettes. - R. de la Fon, Responce de René de la Fon pour les Religieux de la Compagnie de Jésus (Villefranche, G. Grenier, 1599). - F. de la Grâce, La chasse du renard Pasquin, descouvert et pris dans sa tannière du libelle diffamatoire faux-marqué le Catéchisme des Jésuites (Villefranche, Hubert le Pelletier, 1602). - F. des Montaignes, La vérité défendue pour la Religion catholique en la cause des Jésuites (Turin, Michel Gaillard, 1595). - L. Richeome, Plainte apologétique au Roy Tres-Chrestien de France et de Navarre, pour la Compagnie de Jésus (Bordeaux, S. Millanges, 1602). - Très-humble remonstrance et requeste des religieux de la Compagnie de Jésus au Tres-Chrestien Roy de France et de Navarre Henri IIII (Bordeaux, S. Millanges, 1598). - Sur ce sujet voir: H. Bremond, Histoire littéraire du sentiment religieux (Paris, Bloud et Gay, 1916), I: 17-67.

117 Dans les Recherches, III, XLIV. Ecrit et prononcé en 1565, le Plaidoyer fut imprimé pour la première fois à Paris en $1594 \mathrm{chez}$ Abel Langelier et inclus dans l'édition du troisième livre des Recherches en 1596. 118 E. Pasquier, Lettres, XXII : xii, col. 683B. 
de suppléer les carences du fond en ressassant longuement les arguments agités contre les Jésuites depuis leur arrivée en France; ${ }^{119}$ il va même jusqu'à leur adresser les quolibets habituels contre les religieux, inlassablement répétés depuis des générations. La mesquinerie et la gratuité de certaines de ces accusations, les outrances de langage qui les accompagnent souvent, en diminuent de beaucoup la valeur et la portée. Mais peut-être la nature même du procès et l'exaspération des passions qu'il déchaîna ne permettaient pas qu'il en fût autrement. Certains points du réquisitoire toutefois portent davantage et ils témoignent d'une perspicacité que la ferveur gallicane de Pasquier rendait singulièrement aiguë.

Son dessein en tout cas est de prouver que le programme et les ambitions cachées ou avouées de la Compagnie de Jésus infirment systématiquement les coutumes gallicanes et mettent par conséquent en péril les institutions françaises, et au premier chef, les institutions universitaires. C'est d'ailleurs là l'objet principal du présent débat. Dès le début du Plaidoyer Pasquier prononce un vibrant panégyrique de l'Université de Paris où il montre que celle-ci s'est signalée, tant par la qualité de son enseignement que par sa fidélité inaltérable au roi et à l'idée gallicane. Il ne fait aucun doute dans son esprit que les Jésuites ne sauraient transgresser la tradition universitaire qui interdit aux moines de faire cours en dehors de leur couvent et à d'autres étudiants que ceux de leur ordre. ${ }^{120}$ La demande d'incorporation du Collège de Clermont à l'Université de Paris est donc irrecevable. Le problème est toutefois moins simple qu'il ne paraît à première vue car les Jésuites refusent de se définir comme réguliers ou comme séculiers. Aussi Pasquier tente-t-il de les enfermer dans un dilemme: si la Compagnie est un ordre régulier elle ne peut dispenser publiquement son enseignement; si au contraire elle veut être incorporée sous le nom de Société du Collège de Clermont conformément à l'Acte de Poissy, alors elle contrevient à ses bulles de fondation et à ses Constitutions. ${ }^{121}$

Pour mieux convaincre ses auditeurs ... et lecteurs, Pasquier élargit délibérément le débat pour prouver que la vocation universitaire des Jésuites ne peut qu'engendrer en ce domaine

119 Il utilisa assurément les pièces des poursuites intentées par l'Université et le clergé contre les Jésuites depuis 1551, comme par exemple la censure de la Faculté de théologie de 1554 qu'il cite in extenso. Recherches, III : xliv, col. 339ABC-340A. On les retrouve pour la plupart dans Duplessis d'Argentre, Collectio judiciorum de novis erroribus (Paris, Cailleau, 1728), II : 1 , passim.

120 E. Pasquier, Recherches, III : xliii, col. 327-338.

121 Ibid., III : xliv, col. 338ABC. 
des abus intolérables: la corruption de la jeunesse d'abord, qui amènera celle-ci à épouser leurs vues; ${ }^{122}$ la gratuité de l'enseignement ensuite ${ }^{123}$ - il se garde bien de parler de sa qualité! qui risque fort de ternir le renom - mais il l'est depuis longtemps et Pasquier n'en dit mot - de l'Université de Paris. Qui plus est: il apparaît que cette vocation universitaire n'est que l'un des aspects d'un plan soigneusement concerté, autrement plus ambitieux, et partant, plus dangereux: leur privilège de pouvoir conférer les sacrements sans leur permission sapera à coup sûr l'autorité des évêques; ${ }^{124}$ devenus grâce au vœu de mission les agents du pape, ${ }^{125}$ espagnols ou italiens pour la plupart par surcroît, ${ }^{126}$ les Jésuites menacent directement la sécurité du roi et celle du royaume; ${ }^{127}$ ils ne manqueront pas - éventualité redoutable en cette période de guerre civile - de diviser, par leurs agissements, les catholiques en deux camps. ${ }^{128}$ Certes en 1565 il ne pouvait s'agir là que d'hypothèses, de suppositions, voire de prémonition; toutefois, fondées ou non, celles-ci seront considérées comme des réalités moins de quarante ans plus tard. Pasquier ne manquera pas de les reprendre et de les étayer plus solidement dans son Catéchisme des Jésuites. ${ }^{129}$

Cet ouvrage est donc, à plus d'un égard, un prolongement du Plaidoyer, tant il est vrai que nombre de conclusions de celui-ci se retrouvent dans celui-là. Toutefois, la question primordiale en 1565 de l'incorporation du Collège de Clermont à l'Université est à peine effleurée. Ce qui importe maintenant, c'est le rôle politique et religieux de la Compagnie de Jésus en France et en Europe.

Cette évolution de la situation tient à plusieurs facteurs. La réforme catholique et la Ligue, nous l'avons vu, ont exacerbé les passions gallicanes et ultramontaines et créé un climat éminemment propice à la controverse. D'autre part, la Compagnie

122 Ibid., III : xliv, col. $349 \mathrm{~B}$.

123 Ibid., III: xliv, col. 348-349.

124 Ibid., III : xliv, col. 343-345.

125 Ibid., III: xliv, col. $345 \mathrm{C}$.

126 Ibid., III : xliv, col. 338CD.

127 Ibid., III : xliv, col. 345-347.

128 Ibid., III: xliv, col. $346 \mathrm{~A}$.

129 Une lettre de Pasquier à Saincte-Marthe jette quelque lumière sur les raisons qui le poussèrent à rédiger le Catéchisme des Jésuites (Lettres, XXI: ii, col. 633AB). Il s'était lié d'amitié avec Robert Bruce, un Ecossais qui avait eu maille à partir avec la Compagnie de Jésus (cf. le Catéchisme, III: ii). Ce dernier lui avait communiqué la Response de René de la Fon (cf. supra note 116) que ses amis, en raison du ton violemment hostile que l'auteur avait adopté à son égard, lui avaient jusqu'alors cachée. La lecture de ce livre "placart de honte, calomnies, impostures et asneries contre moi dictes" le poussa, semble-t-il, à se mettre à la tâche sur-le-champ. 
de Jésus est devenue un ordre religieux de tout premier plan. On lui envie, certes, sa remarquable organisation, la discipline et la valeur de ses membres, ses succès incontestables dans le domaine de l'éducation, de la direction spirituelle et de la propagation de la foi; mais elle inquiète précisément par sa puissance internationale aux multiples ramifications, par ses privilèges nombreux et, d'aucuns le prétendent, exorbitants, par son désir d'enrayer la laïcisation de l'Etat, par sa sujétion, enfin, à la papauté et peut-être même à l'Espagne, à moins murmure-t-on, qu'elle ne les ait circonvenues l'une et l'autre. Ses ennemis en tout cas prennent prétexte de quelques écrits imprudents, de rumeurs de subversion et de conspiration dans les pays protestants et même catholiques, pour brosser le tableau, devenu depuis lors un cliché, du Jésuite ambitieux, insinuant, sans scrupule, hypocrite, assassin au besoin et toujours par personne interposée. Il n'en fallait pas tant pour que toutes les craintes réelles ou feintes, toutes les rancœurs, tous les ressentiments s'exhalent. Et Pasquier saura les rassembler et les propager dans ce vaste répertoire des "turpitudes" de la Compagnie de Jésus qu'est le Catéchisme.

Cet ouvrage est le fruit d'une somme considérable de recherches et de réflexions car Pasquier ne voulait pas être en reste dans cette guerre des livres où partisans et adversaires des Jésuites faisaient assaut d'érudition, au risque d'ailleurs de verser dans la cuistrerie. Aussi ses sources sont-elles nombreuses et variées. A celles - bien minces en vérité, nous l'avons $\mathrm{vu}$ - qu'il avait utilisées en 1565 viennent sans doute s'ajouter des pamphlets, satires, plaidoieries et arrêts de tous ordres composés au cours du dernier quart du XVIe siècle. ${ }^{130}$ Cependant

${ }^{130} \mathrm{La}$ question, à vrai dire, peut être débattue, car Pasquier ne fait guère mention des travaux de ses prédécesseurs, à l'exception de ceux d'Arnauld, Dollé et Marion. Il n'avait sans doute que faire d'un bon nombre d'entre eux; il était en effet parfaitement au courant des activités de la Compagnie de Jésus en France aussi bien que des documents d'archives qui s'y rapportaient. Il nous paraît toutefois impensable qu'il ait ignoré l'existence de ces écrits et qu'il n'en ait pas utilisé quelques-uns. Nous pensons en particulier à ceux - et ce sont pour la plupart des traductions - qui concernaient les complots des Jésuites en Angleterre et aux Pays-Bas. Son ignorance de l'anglais et du néerlandais l'obligeait pratiquement à y recourir. D'autre part la teneur de la lettre adressée à Saincte-Marthe (cf. supra note 129) montre que Bruce avait fourni à Pasquier un certain nombre d'ouvrages - anglais peut-être, et dans ce cas il les lui aurait traduits consacrés aux Jésuites. D. Thickett, Bibliographie ... p. 20-21, a pu établir, en se servant de la correspondance entre Nevill, ambassadeur d'Elizabeth I à Paris, et Robert Cecil, secrétaire d'Etat, que Bruce avait demandé à ce dernier de lui en faire parvenir d'autres. Nevill rapporte par ailleurs que Pasquier travaillait en étroite collaboration avec son ami écossais à la 
il accorde la plus grande importance aux témoignages émanant de la Compagnie elle-même et dont il se sert comme repoussoir : les Constitutions ${ }^{131}$ qu'il semble bien connaître et qu'il cite largement; les œuvres de Jésuites éminents comme Ribadeneyra, Emmanuel de Sà, Richeome.132

Réquisitoire fort bien structuré en dépit de quelques redites et digressions, le Catéchisme comprend trois thèmes étroitement liés les uns aux autres: le premier est un substantiel rappel historique consacré aux origines de la Compagnie et à sa première réception en France; le deuxième est une analyse des Constitutions où Pasquier s'efforce de prouver que celles-ci inspirent et motivent l'action des Jésuites; le troisième enfin qui répond à l'hypothèse posée dans le précédent est un relevé systématique des méfaits de la Compagnie; c'est elle qui, portant l'essentiel du message du Catéchisme, doit provoquer chez les lecteurs l'impression la plus vive.

Que la création de la Compagnie de Jésus soit entachée d'irrégularités ne fait aucun doute pour Pasquier. La falsifica-

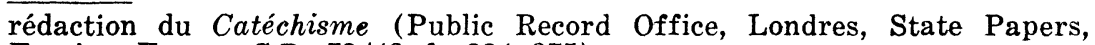
Foreign, France, S.P., 78/43, fos 324,375$)$.

Dans le cadre d'une étude plus vaste sur Pasquier nous préparons actuellement un travail sur les pamphlets anti-jésuites composés à la fin du XVIe siècle et qui répondra, du moins nous l'espérons, à quelques-unes des hypothèses que nous avons formulées dans cette note. Sans vouloir fournir ici une liste exhaustive de ces pamphlets, nous en présentons quelques-uns à titre d'exemple: "Advertissement sur la conjuration faitte par la Ligue contre la Royne d'Angleterre par l'entremise de quelques jeunes gentilshommes séduits par les Jésuites, et des exécutions qui en furent faittes", dans S. Goulart, op. cit., II : 285-297. - A. Arnauld, op. cit. Complaincte des escolliers contre les nouveaux violateurs des lois surnommez Jésuites (s.l., 1565). - "La conspiration faicte par les pères Jésuites de Douay, pour assassiner Maurice prince d'Orange, Comte de Nassau", dans S. Goulart, op cit., VI: 717-723. - Discours veritable de diverses conspirations naguères descouvertes contre la propre vie de la très excellente maiesté de la roine; par assassinement autan barbares comme sa conservation a esté miraculeuse (Londres, Yetsweirt, 1594). Le même texte a été réédité à deux reprises, sous un titre légèrement différent. L'une en 1595 à Paris, l'autre en 1598 dans S. Goulart, op. cit., tome V: 324-337. - L. Dollé, Plaidoyé de M. L. Dollé advocat en la Cour de Parlement pour les curez de la ville de Paris demandeurs contre les Jésuites défendeurs, des 13 et 16 juillet 1594 (Paris, Mamert Patisson, 1595). - "Histoire véritable de la conspiration de Guillaume Parry Anglois contre la Royne d'Angleterre, depuis l'an 1584", dans S. Goulart, op. cit., I : 10-63. - S. Marion, Plaidoyé sur lequel a esté donné contre les Jésuites l'arrest du 16 octobre 1597 inséré à la fin d'iceluy (Paris, Mamert Patisson, 1597).

$131 \mathrm{E}$. Pasquier, Le Catéchisme des Jésuites, II: v, fo 129vo. Peut-être s'agit-il ici du texte $\mathrm{C}$ des Constitutions.

${ }_{132}$ P. Ribadeneyra, Vita Ignatii Loiolae (Anvers, Plantin, 1587). E. de Sà, A phorismi confessariorum (Paris, Pierre Chevalier, 1600). - Sur Richeome, cf. supra, note 116. 
tion de leurs diplômes, ${ }^{133}$ le nom même de Jésuites ${ }^{134}$ et le vœu particulier au pape, ${ }^{135}$ montrent clairement qu'Ignace de Loyola et ses premiers compagnons n'ont rien négligé pour circonvenir Paul III et obtenir de lui la reconnaissance officielle de l'Ordre. De ce fait la bulle de 1540 doit être considérée comme nulle et non avenue. ${ }^{136}$ Par un raisonnement qui ne laisse pas d'être subtil et que l'on retrouve en filigrane tout au long du Catéchisme, Pasquier suggère que la papauté est la victime, et au pire la comparse des Jésuites; c'est donc à eux que tout l'odieux de la réforme tridentine doit être imputé.

Consciente du danger que couraient les évêques, les anciens ordres religieux et l'Université, l'Eglise de France a fait montre au contraire de courage et d'énergie. La censure de la Faculté de Théologie en 1554, le décret de Poissy, le procès de 1565 en sont une preuve suffisante; mais ils témoignent du danger constant qui menace ce dernier bastion dressé contre les Jésuites. ${ }^{137}$ Et pour permettre à ses lecteurs de mesurer plus exactement encore tout ce qui les sépare, Pasquier dresse une liste de 52 incompatibilités entre les propositions de la Compagnie de Jésus et les libertés de l'Eglise gallicane dont la teneur, d'ailleurs, s'inspire largement des idées maîtresses exprimées dans le troisième livre des Recherches de la France. ${ }^{138}$

Passant ensuite à l'étude des Constitutions, Pasquier constate avec plaisir que la plus grande diffusion de celles-ci de même que les commentaires qui en avaient dégagé l'esprit, éclairé le sens et fixé les modes d'application lui ont singulièrement facilité la tâche. A son avis, une telle publicité, peu conforme à l'habituelle discrétion des Jésuites, dessert leurs intérêts et profite en fin de compte à leurs ennemis. ${ }^{139}$ Il ne pouvait être question que Pasquier analyse en détail chaque article des Constitutions; il dut opérer un choix et c'est en fin de compte la question des vœux qui retint le plus son attention en raison des conséquences que ceux-ci devaient, à son sens, engendrer. Et d'abord les vœux simples. Il leur dénie toute valeur canonique puisqu'ils ont un caractère, en quelque sorte provisoire et conditionnel. Que le Préposé général ou même un provincial puisse renvoyer quand bon lui semble celui qui les a prononcés, Pasquier l'interprète comme le signe évident d'une manœuvre de la Com-

133 E. Pasquier, op. cit., I: xi-xii.

134 Ibid., I : viii.

135 Ibid., II : xvi.

138 Ibid., I : xiii.

137 Ibid., I: iii-vi.

138 Ibid., II : i.

139 Ibid., II: xix, fos $192 \mathrm{r}^{\circ}-194 \mathrm{v}^{\circ}$. 
pagnie pour peupler la chrétienté d'anciens clercs qui lui resteraient - par définition - tout dévoués. ${ }^{140}$ C'est toutefois le vœu de mission qui l'inquiète le plus; il en avait déjà signalé les dangers quarante ans plus tôt et il avait vu son opinion partagée par le nombre croissant de tous ceux qui faisaient profession de dénoncer les errements de la Compagnie. Pour sa part il y voit une double imposture: la fidélité au pape, en apparence sans faille, que ce vœu implique, n'est qu'un leurre, car le souci qu'ont les Jésuites de défendre âprement leurs propres intérêts les incite, le cas échéant, à la marchander, quand ils ne la renient pas; ils se sont détournés d'autre part de leur lieu d'apostolat primitif qui devait être l'Empire ottoman pour s'implanter en terre chrétienne, rendant caduque, de ce fait, la notion même de mission. ${ }^{141}$ Ils n'ont pas tardé à y sévir et c'est sur la relation de leurs forfaits que Pasquier compte pour les discréditer.

En puisant largement dans des témoignages de toute provenance et de toute créance il réussit à constituer un lourd dossier. Il espère ainsi faire la preuve de l'existence d'une vaste conspiration de la Compagnie dans les états laïques comme dans l'Eglise universelle et mettre en garde l'opinion publique française que la crise dynastique récente avait rendu particulièrement attentive à tout ce qui touchait la sécurité du roi, le maintien des institutions traditionnelles et l'indépendance du royaume. Il n'est pas de moyens que les Jésuites n'aient utilisés pour rendre ce péril redoutable: par la confession ils peuvent aisément percer le secret des consciences, partant, découvrir le ressort des événements, et, s'il leur sied, en modifier le cours en circonvenant leurs pénitents ;42 $^{14}$ d'ailleurs ils promettent le ciel à quiconque les aide à réaliser leurs desseins; leurs collèges leur permettent, certes, d'acquérir un véritable monopole de l'enseignement au détriment de l'Université, 143 mais surtout, ils y chambrent les élèves, les soustraient à l'autorité de leurs parents et suscitent de la sorte des vocations dont Pasquier conteste évidemment la valeur; il n'en veut pour preuve que l'affaire d'Ayrault, présente dans toutes les mémoires à l'époque, en raison du scandale qu'elle provoqua $;^{144}$ les Jésuites professent enfin la

140 Ibid., II : ix-xv.

141 Ibid., II : xvi-xviii.

142 Ibid., III : xii.

143 Ibid.. II : vi.

144 Ibid., II: iv et viii. Pierre Ayrault, lieutenant criminel, au siège présidial d'Angers intenta sans succès en 1586 un procès aux Jésuites pour le rapt de son fils. Sur cette question voir: $\mathrm{P}$. Ayrault, De la puissance paternelle. Contre ceux qui sous couleur de religion vollent les enfants à leurs pères et mères (Tours, Jamet Mettayer, 1593) ; Conclusion de l'ordre, formalité et instruction judiciaire, de P. Ayrault, lieutenant criminel d'An- 
théorie du tyrannicide et soutiennent le droit d'intervention du pape dans les affaires politiques. ${ }^{145}$ Il n'est donc pas étonnant que derrière chaque assassinat, chaque guerre, chaque sédition, se profile l'ombre de la Compagnie de Jésus.

Celle-ci a introduit la Ligue en France en 1585 et par la suite elle lui a toujours accordé son appui;146 en 1593 et 1594 elle a ourdi les tentatives de meurtre de Barrière ${ }^{147}$ et de Chastel ;148 elle n'a réussi en fin de compte qu'à rompre l'unité des Parlements ${ }^{149}$ et à favoriser les Huguenots à qui le roi a accordé l'Edit de Nantes pour prix de leur aide contre elle. ${ }^{150}$ L'Europe non plus n'a pas été épargnée: aux Pays-Bas, les Jésuites ont fait assassiner Guillaume d'Orange et ils n'ont échoué que de justesse sur la personne de son fils ${ }^{151}$ ils ont été de tous les complots tramés en Angleterre pour renverser la reine Elizabeth; ${ }^{162}$ ils ont commis de semblables forfaits en

gers, à René Ayrault son fils (s.l., 1588). - P. de Musset, Histoire de P. Ayrault et de son fils René pseudo-jésuite (Paris, E. Dentu, 1879).

145 E. Pasquier, Le Catéchisme des Jésuites, III: i, v et xvii. 146 Ibid., III : xi.

147 Ibid., III: vi. Dans son édition critique des Ecrits politiques de Pasquier, p. 247-8, D. Thickett lui attribue la paternité d'un Extraict du procès fait à Pierre Barrière dit la Barre, natif d'Orléans, accusé de l'horrible et exécrable parricide et assassinat par luy entrepris et attenté contre la personne du Roy (Tours, 1593) qu'il avait dressé à l'invitation d'Henri IV. Il s'en servit pour composer peu après un écrit plus étoffé sur le même sujet: Histoire prodigieuse d'un détestable parricide entrepris sur la personne du Roy, par Pierre Barrière, dit la Barre, et comme sa Majesté en fut miraculeusement garentie (s.l., 1594), dont il inclut de larges extraits, presque mot pour mot, dans le Catéchisme, III : vi.

148 E. Pasquier, Le Catéchisme des Jésuites, III : viii.

149 Ibid., III : xxi.

150 Ibid., III : xi, fos $240 \mathrm{v}^{0}-241 \mathrm{r}^{\circ}$.

151 Ibid., III: i, fo 202 vo. Voir en particulier: J. Andriessen, De Jezuieten en het Samenhorigheidsbesef der Nederlanden, 1585-1648 (Anvers, Nederlandsche Boekhandel, 1957), 229-247.-Bollandus?, Imago primi saeculi Societatis Jesu Antverpiae (Balthasar Moretus, 1640) VI: iv. - Les cruels et horribles tormens de Balth. Gérard, vray martyr, soufferts en l'exécution de sa glorieuse et mémorable mort pour avoir tué Guill. de Nassau, prince d'Orange, ennemy de son Roy et de l'Eglise catholique (Paris, 1585). Sica tragica comiti Mauritio, ut ajunt Calvinistae a Jesuitis Leydae intentata per costerum (Anvers, 1599) ; cf. aussi supra note 130.

152 S. Pasquier, Le Catéchisme des Jésuites, III: iii, iv, xv. La bibliographie est presqu'inépuisable en raison des controverses passionnées que cette question a soulevées et soulève encore entre historiens catholiques et protestants. Depuis quelques années la discussion est plus sereine et il semble bien que même ceux-ci ne souscrivent plus entièrement à l'affirmation péremptoire de Waldman, Elizabeth Qween of England (Londres, Longmans, Green and Co, 1933), 282, pour lequel "without exception every plot for Elizabeth's assassination could be traced to one of the Jesuit missionnaries". Il est toutefois évident que la Papauté, la Compagnie de Jésus ou du moins quelques-uns de ses membres, n'ont pas été étrangers à 
Ecosse, ${ }^{153}$ en Pologne et en Suède;154 Pasquier laisse même à entendre qu'ils ont hâté la mort du pape Sixte-Quint qui passait pour être favorable à Henri IV. 155

Ces différentes initiatives servent si bien les intérêts de l'Espagne qu'il serait légitime de croire que les Jésuites sont à la solde de ce pays. Pasquier récuse toutefois cette interprétation car il estime qu'ils n'ont d'autre but que de faire avancer leurs affaires en utilisant qui bon leur semble. ${ }^{156}$

Le seul résultat tangible de l'activité des Jésuites est qu'ils mettent en péril l'existence même des structures ecclésiastiques et politiques de l'Europe chrétienne et à ce titre ils lui ont fait plus de tort que les Luthériens. ${ }^{157}$ En tirant avantage de leurs rapports étroits avec la papauté ils ont obtenu de son imprudence et de sa faiblesse des privilèges exorbitants qui sont autant d'étapes vers la conquête du pouvoir et, par voie de conséquence, l'abaissement de la dignité pontificale, la destruction des libertés gallicanes et la soumission des Etats.

Il serait certes intéressant d'évaluer l'influence de Pasquier sur l'évolution du gallicanisme aux XVIIe et XVIIIe siècles comme E. Préclin l'a fait pour Edmond Richer. ${ }^{158}$ Nous espérons pouvoir y parvenir dans un travail qui est actuellement en cours d'élaboration. Il n'est toutefois pas inutile d'esquisser ici quelques hypothèses de travail. Pasquier a appartenu à cette géné-

un bon nombre de ces complots. Quant à Elizabeth, elle tenta plus d'une fois de faire assassiner le pape. Voir à ce sujet: J. Bossy, Elizabethan Catholicism: the link with France, thèse dactylographiée (Cambridge, 1961) ; "Henri IV, the Appelants and the Jesuits", dans Recusant history, VIII (1965): 80-112. - P. Caraman, The other face. Catholic life under Elizabeth $I$ (Londres, 1960). - T. Clancy, "English Catholics and the Papal deposing power, 1570-1640", dans Recusant History, VI (1961-2): 114-140, 205-227. - D. Hay, The Jesuits and the Popish plot (Londres, 1934). - L. Hicks, "The strange case of Dr. William Parry: the career of an agent-provocateur", dans Studies (Dublin), 37 (1948): 343-362. P. Hughes, Rome and the Counter-Reformation in England (Burns Oates, 1944). - R. Lechat, Les réfugiés anglais dans les Pays-Bas espagnols (1558-1603) (Louvain, 1914). - J. H. Pollen, "The politics of the English Catholic during the reign of Queen Elizabeth", dans The Month, (1902): 43-60, 131-148, 290-305, 394-411, 600-618; (1903) : 71-87, 176-188. Cf. aussi supra note 130.

153 E. Pasquier, Le Catéchisme des Jésuites, III : ii.

154 Ibid., III : xvi, fo $256 \mathrm{r}^{\circ} \mathrm{v}^{\circ}$.

155 Ibid., I: ii, fo $15 \mathrm{r}^{\circ}$.

156 Ibid., III : xiv.

157 Ibid., III : xxiv.

158 E. Richer, Libellus de ecclesiastica et politica potestate (Paris, 1611). 
ration d'historiens et de juristes qui, à la fin du XVIe siècle, ont formulé, défini et justifié avec plus ou moins de bonheur les libertés gallicanes. Aucun d'entre eux n'a joui jusqu'à ce jour d'une faveur aussi grande que celle de Pierre Pithou dont le Traicté des libertez de l'Eglise gallicane ${ }^{159}$, clair et concis, assorti en outre au siècle suivant de commentaires et de preuves par le grand érudit Pierre Dupuy ${ }^{160}$, a été le livre de chevet de tous les Gallicans jusqu'au XIXe siècle. Cette renommée a rejeté dans l'ombre tous les autres auteurs, si bien que l'analyse de leurs œuvres reste encore, dans la plupart des cas, à faire.

Pasquier n'a pas échappé au sort commun. Et pourtant il fut suffisamment estimé aux XVIe, XVIIe et XVIIIe siècles pour que ses Recherches de la France ne connaissent pas moins de 17 éditions. ${ }^{161}$ Leur diffusion dans les bibliothèques, relevée patiemment par D. Thickett, laisse d'ailleurs supposer que les tirages étaient relativement importants. ${ }^{162}$ Toutefois la diversité des sujets qui y sont abordés tels que l'histoire de la langue, de la littérature, des institutions universitaires, ecclésiastiques et monarchiques, brouille en quelque sorte les pistes et nous empêche jusqu'à nouvel ordre de discerner si c'est le livre III, consacré aux libertés gallicanes, qui leur a valu une telle audience. Il faudrait à cet égard étudier le cheminement des idées de Pasquier dans les travaux gallicans ultérieurs et y relever des références précises.

Il semble que la tâche soit relativement plus aisée pour le Plaidoyer et pour le Catéchisme. Il est probable que les démêlés célèbres de leur auteur avec la Compagnie de Jésus autant que les copieuses vitupérations qu'il adressa à cette dernière, firent considérer ces deux ouvrages comme une mine de renseignements et une source d'inspiration incomparables pour tous ceux qui, catholiques ou protestants, français ou étrangers, faisaient profession d'antijésuitisme.

Toute étude sur Pasquier et sur son influence amène nécessairement à poser une fois de plus le problème du contenu et de la destinée du gallicanisme. Il n'existe à l'heure actuelle aucun livre d'importance sur son histoire depuis la fin du Moyen Age jusqu'à ses épigones au XIXe siècle. Assurément des synthèses partielles lui ont été consacrées: c'est ainsi que Victor

159 (Paris, Mamert Patisson, 1594).

160 Preuves des libertez de l'Eglise gallicane (s.l., 1639). - Commentaire sur le Traicté des libertez de l'Eglise gallicane de maistre Pierre Pithou (Paris, Cramoisy, 1652). 161 D. Thickett, Bibliographie ......, 32-44.

162 Ibid., 10. 
Martin en a étudié les origines jusqu'en $1438 ; 163$ nous devons nous contenter pour les siècles suivants de monographies, souvent excellentes, mais nécessairement restreintes. La tâche est d'ailleurs immense: il faudrait mesurer la permanence mais aussi la mutation de ses thèmes et de ses institutions à travers les œuvres doctrinales et la pratique des Cours de Parlement, de l'Université ou des Assemblées du clergé, identifier les courants de pensée qui l'ont traversé,164 évaluer la part des influences extérieures, étudier ses relations avec l'état social, distinguer, le cas échéant, ses diversités régionales. ${ }^{165}$ Une telle entreprise devrait évidemment tenir compte de ses prolongements en dehors de la France et notamment au Canada. Il y a de bonnes pages consacrées à ce dernier point. Elles font ressortir l'existence sous le régime français d'un gallicanisme importé de toute pièce de la métropole. ${ }^{166} \mathrm{Ne}$ conviendrait-il pas de multiplier ces coups de sonde ? La question est plus complexe par la suite et l'on peut se demander si la poussée du milieu du siècle dernier ne serait pas au fond, comme en France, qu'un gallicanisme au petit-pied, émasculé, vidé d'une partie de sa substance, en un mot une tendance gallicanisante assez éloignée de ses origines et de ses maîtres à penser du XVIe et du XVIIe siècles. Dans son JulesPaul Tardivel Pierre Savard a montré l'étonnante complexité des mouvements ultramontains et gallicans au Canada français, leur répercussion sur le plan politique et aussi la nécessité de ne pas les séparer de leurs sources européennes. ${ }^{167}$ Il nous donne ainsi une idée du travail qui attend les futurs chercheurs.

Université de Montréal

Claune Sutto

163 Les origines du gallicanisme (Paris, Bloud et Gay, 1939).

$164 \mathrm{E}$. Preclin a étudié les influences réciproques du jansénisme et du gallicanisme dans Les Jansénistes du XVIII' siècle et la Constitution civile du clergé (Paris, J. Gamber, 1928).

165 Considérées comme pays d'obédience la Bretagne et la Provence n'ont été astreintes au régime concordataire qu'en 1586. Quant aux TroisEvêchés ils restèrent soumis au régime du Concordat germanique jusqu'au XVII' siècle.

166 Joseph Cossette, "Jean Talon, champion au Canada du gallicanisme royal, 1665-1672", dans Revue d'histoire de l'Amérique française, XI (1957): 327-352. - Guy Frégault, La civilisation de la Nouvelle-France (Montréal, Société des Editions Pascal, 1944). - Lionel Groulx, "Le gallicanisme au Canada sous Louis XIV", dans Revue d'histoire de l'Amérique française, I, (1947): 54-90. - G. 'Lanctôt, "Situation politique de l'Eglise canadienne sous le régime français", dans La Société canadienne d'histoire de l'Eglise catholique, Rapport 1940-41: 35-56.

167 (Québec, P.U.L., 1967). - Cf. aussi P. Sylvain, "Quelques aspects de l'antagonisme libéral-ultramontain au Canada français", dans Recherches sociographiques, VIII (1967): 275-297. 